\title{
Influence of (de)protonation on the photophysical properties of phenol-substituted diazine chromophores: experimental and theoretical studies
}

Maxime Hodée, ${ }^{\mathrm{a}}$ Augustin Lenne, ${ }^{\mathrm{a}}$ Julian Rodríguez-López, ${ }^{\mathrm{b}}$ Françoise Robin-le Guen, Claudine Katan, ${ }^{a}$ Sylvain Achelle, ${ }^{\mathrm{a}^{*}}$ and Arnaud Fihey. ${ }^{\mathrm{a}^{*}}$

${ }^{\text {a } U n i v ~ R e n n e s, ~ E N S C R, ~ C N R S, ~ I S C R ~(I n s t i t u t ~ d e s ~ S c i e n c e s ~ C h i m i q u e s ~ d e ~ R e n n e s) ~-~ U M R ~}$ 6226, F-35000 Rennes, France. E-mails: sylvain.achelle@univ-rennes1.fr, arnaud.fihey@univ-rennes1.fr

${ }^{\mathrm{b}}$ Universidad de Castilla-La Mancha, Área de Química Orgánica, Facultad de Ciencias y Tecnologías Químicas, Avda. Camilo José Cela 10, 13071 Ciudad Real, Spain

TOC

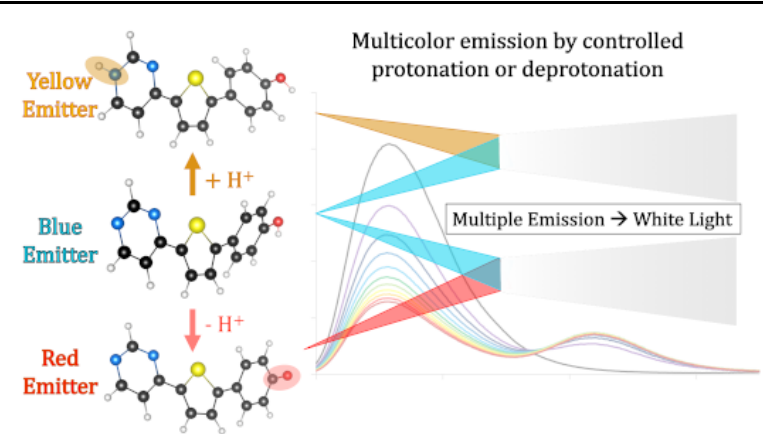

With the help of (TD)-DFT calculations, white light emission in solution is reached by controlling the (de)protonation of diazine heterocyclic chromophores.

\begin{abstract}
In this contribution, a series of seven new push-pull systems has been designed by combining a protonable diazine heterocycle (pyrimidine/pyrazine) with a deprotonable phenol unit through various $\pi$-conjugated linkers (phenylene, thienylene, thienylenevinylene, and phenylenevinylene). The (de)protonation in solution resulted in a systematic bathochromic shift both in the absorption and emission maxima compared to the neutral forms. Extensive Density Functional Theory (DFT) and its Time Dependent counterpart (TD-DFT) calculations were performed to rationalize this behavior and understand the impact of (de)protonation on the different optical transitions. These computations showed that (de)protonation affects both
\end{abstract}


the energy and the nature of the vertical transitions, with a significant increase in the Intramolecular Charge Transfer (ICT) character of the (de)excitations. Some of the compounds remained moderately luminescent after (de)protonation, giving a mixture of complementary emitting species that were used to obtain white light emission.

Keywords: Intramolecular charge transfer; Diazine; Pyrimidine; Phenol; White light emission

\section{INTRODUCTION}

During the past decades, there has been a huge interest in the design of $D-\pi$-A structures simultaneously bearing an electron-donating group (D) connected to an electronwithdrawing (A) fragment via a $\pi$-conjugated linker. ${ }^{1}$ Such structures, also called push-pull compounds, are characterized by an intramolecular charge transfer (ICT) between the D and A groups during the absorption or emission of light. This ICT is the result of a more or less significant displacement of electronic charges on the molecular backbone after the excitation or de-excitation of the system and depends on the structure of the molecule. ${ }^{\text {lc }}$ In any case, the polarization of the $\pi$-system generates a dipole that is responsible for the extraordinary optoelectronic properties of push-pull derivatives, often characterized by multicolor emission properties and high nonlinear optical (NLO) responses. Push-pull chromophores have been therefore extensively used as fluorophores for bio-imaging, ${ }^{2}$ active components for photovoltaic devices (dye-sensitized solar cells, ${ }^{3}$ bulk heterojunction solar cells, ${ }^{4} \ldots$ ), emitters for OLEDs, ${ }^{5}$ second harmonic generation, ${ }^{6}$ and two-photon absorption. ${ }^{7}$

ICT can be easily tuned by playing with the A/D couple or by modifying the $\pi$ conjugated linker. ${ }^{1 \mathrm{c}}$ The reversible tuning of the ICT in organic push-pull materials is of high interest. For instance, NLO switches based on modulation of ICT have been used for nondestructive data storage and photonic devices. ${ }^{8}$ For a given push-pull system, the modulation of ICT can be the consequence of photo- ${ }^{9}$ or electrostimulation. ${ }^{10}$ It can be also due to the 
reversible bonding of an analyte (proton, ${ }^{11}$ metal cation, ${ }^{12}$ etc.) on the D or A part of the pushpull structure, which is one of the main mechanism of fluorescent sensors. To attain such properties, the molecular design by choosing suitable D and A substituents is a simple way to modulate the photophysical behavior of a $\pi$-conjugated molecule. Binding to the A unit leads to an increase of ICT and a red-shift (or a quenching) in emission, whereas interaction with the D unit results in a reduction of ICT and a blue-shift in emission. ${ }^{13}$ The interplay between these moieties is essential to control the displacement of electronic densities, although it is also necessary to adjust the $\pi$-conjugated linker between them.

Diazine-based molecules are candidates of choice for such a design strategy. Diazine are six-membered heterocycles with two nitrogen atoms. Depending on the position of the nitrogen atoms, pyridazine (1,2-diazine), pyrimidine (1,3-diazine), and pyrazine (1,4-diazine) can be distinguished. Quinoxaline corresponds to benzoannelated pyrazine. Due to the electron-deficient character of these heterocycles, the diazinyl fragments can be considered as electron-withdrawing (A) groups. Thus, numerous push-pull fluorophores based on pyrimidin-4-yl ${ }^{14}$ and pyrazin-2-yl ${ }^{15}$ groups have been described in the literature. Due to the presence of electron lone pairs on the nitrogen atoms, diazines are protonable bases, ${ }^{16}$ they can complex metal cations ${ }^{13,17}$ and bind a large variety of small molecules of biological interest via hydrogen bonding. ${ }^{18}$ Diazines appear therefore as interesting building blocks for the synthesis of fluorescent sensors.

Designing organic fluorophores with multiple emissive signatures is today a key challenge in order to reach domestic lighting with OLEDs. This can be achieved for instance by controlling the Excited State Intramolecular Proton Transfer (ESIPT) equilibrium within a single fluorescent species. ${ }^{19}$ In parallel, during the last few years some of us have designed pyrimidine fluorophores that can emit white light by controlled protonation. ${ }^{20}$ The combination of neutral blue (or purple) emitting species with red (or yellow) emitting 
protonated forms permits to obtain dual panchromatic emission with chromaticity coordinates close to pure white light, both in solution and in the solid state. Thus, these compounds present potential application as emitters for the fabrication of white OLEDs (WOLEDs) with a single material. Recently, Muraoka and coworkers have developed a phenol-substituted pyrazine derivative that showed a qualitative base-responsive fluorescence with red-shifted emission upon deprotonation. ${ }^{21}$ Therefore, both protonation and deprotonation may be targeted in the prospect to develop new emitters for WOLEDs.

In this context, Density Functional Theory (DFT) and its Time Dependent counterpart (TD-DFT) is a tool of choice to rationalize the impact of protonation/deprotonation and contribute to the design of novel emitters. TD-DFT is well known for its reasonable level of efficiency at a decent computational cost. ${ }^{22,23}$ Considering organic dyes, a quite quantitative and accurate description of experimental spectroscopic data in solution (e.g., absorption and emission) can be often achieved, ${ }^{24}$ and TD-DFT stands as a well-suited method to predict and rationalize structure-properties relationships in a series of compounds in solution. Nevertheless, description of charge transfer (CT) excitation in push-pull molecules in this framework remains a tedious computational task, and achieving a qualitative description of such excited states usually requires switching to adapted long-range corrected functionals. ${ }^{25}$ The description of the implicit solvation effects in this situation can be improved by using a state-specific continuum formalism ${ }^{26}$ rather than a linear-response scheme, ${ }^{27}$ although the benefits of such model are highly dependent on the choice of the exchange-correlation functional and the nature of the molecule/excitation of interest. ${ }^{28}$ In addition to the vertical emission properties, it should be noted that predicting the fluorescence quantum yields of extended $\pi$-conjugated molecules with TD-DFT remains an extremely complex task, as it requires modelling the non-radiative de-excitation pathways, which is only tractable for 
model dyes. ${ }^{29}$ This constitutes nowadays the main limitation for a complete rationalization of the experimental light emission behavior.

In this paper, we have designed a series of seven selected phenol substituted diazine chromophores 1-7 with linkers of different nature and length, from simple phenylene or thienylene to more complex phenylenevinylene or thienylenevinylene groups (Figure 1). The methoxy analogue of compound $\mathbf{3}$ was also synthesized to allow comparison between hydroxy and methoxy electron-donating groups. The effect that (de)protonation causes on the photophysical properties is detailed, both through experimental studies by UV-visible absorption and emission spectroscopies and TD-DFT theoretical calculations. The structureproperties relationships of the chromophores are unraveled in order to provide guiding rules for the design of white light emitters.<smiles>NCCN</smiles><smiles>Oc1ccc(-c2ccc(/C=C/c3ccncn3)s2)cc1</smiles>

2<smiles>Oc1ccc(-c2ccc(/C=C/c3ccncn3)cc2)cc1</smiles>

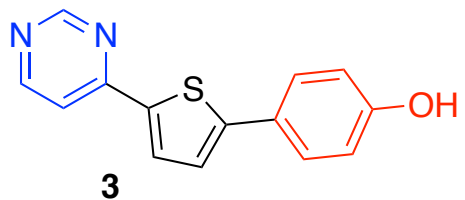

3<smiles>Oc1ccc(-c2ccc(-c3cnc4ccccc4n3)s2)cc1</smiles><smiles>Oc1ccc(-c2ccc(-c3cnccn3)s2)cc1</smiles><smiles>COc1ccc(-c2ccc(-c3ccncn3)s2)cc1</smiles>

Figure 1. Structures of the diazine-based compounds studied in this work.

\section{RESULTS AND DISCUSSION}


To better understand the structure properties relationships in the series of flurophores 1-7, the discussion is organized as follows. After a description of the synthesis procedures, we first detail the theoretical ground state geometries and the electronic structures of these compounds, as obtained at the DFT level. Computed absorption and emission characteristics are then thoroughly analyzed and linked to the nature of the diazine, with quantification of their charge transfer character, followed by corresponding spectroscopic measurements which solidify those predictions. A theoretical description of the effect of the (de)protonation on those properties is finally proposed, and the experimental change in emission upon acid/base addition is presented to identify potential white light candidates in the prospect to design WOLEDs.

\subsection{Synthesis of compounds}

Compounds 2-7 were obtained with moderate to good yield by palladium catalyzed SuzukiMiyaura cross coupling reaction from the appropriate bromo-substituted precursors and 4hydroxyphenylboronic acid pinacol ester following a standard protocol (Scheme 1). The methoxy analogue of compound 3 (3OMe) was obtained under similar conditions in $81 \%$ yield by using 4-methoxyphenylboronic acid. It should be noted that chromophore 1 could not be prepared due to difficulties with the synthesis of the bromo precursor. All compounds were characterized by ${ }^{1} \mathrm{H}$ and ${ }^{13} \mathrm{C}$ NMR as well as HRMS. The signal of the hydroxy group is not visible in all ${ }^{1} \mathrm{H}$ NMR spectra although the large bands observed around $3000-3500 \mathrm{~cm}^{-1}$ in the IR spectra confirm the presence of the phenolic fragment. The ${ }^{3} J(\mathrm{H}-\mathrm{H})$ coupling constants of $\sim 16 \mathrm{~Hz}$ for the vinylic protons of compounds 2,4 , and 7 indicate that the $(E)$-configuration of the starting materials was preserved in the process.
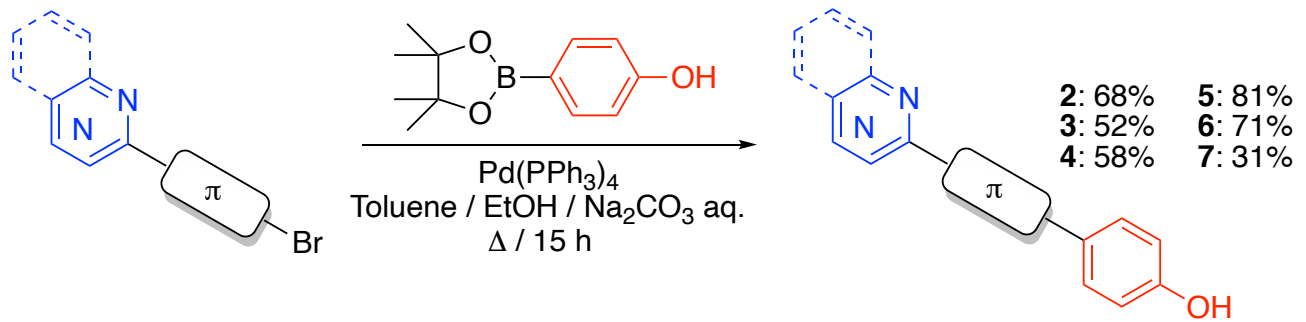

Scheme 1. Synthesis of chromophores 2-7. 


\subsection{Computed ground-state properties}

Several configurations and conformations can be envisioned for the ground states (GS) of the chromophores of interest. Since compounds 2, 4, and 7 encompass a vinyl moiety, they can exhibit geometric isomerism (Figure 2). Using DFT calculations and considering DMSO as the solvent, we found that the $(E)$ stereoisomers are the most stable in all cases. Computed Gibbs free energy differences and the corresponding Boltzmann populations predict that only the $(E)$ isomers are present in solution (Table S1, Supporting Information). In addition, two different conformations can potentially coexist for derivatives $\mathbf{3}, \mathbf{3 0 M e}, \mathbf{5}$, and $\mathbf{6}$, either with a nitrogen of the diazine ring in the neighborhood of the thiophene sulfur atom (conformation A) or on the opposite side (conformation B) (Figure 2). The former was always found to be lower in energy (Table S1).

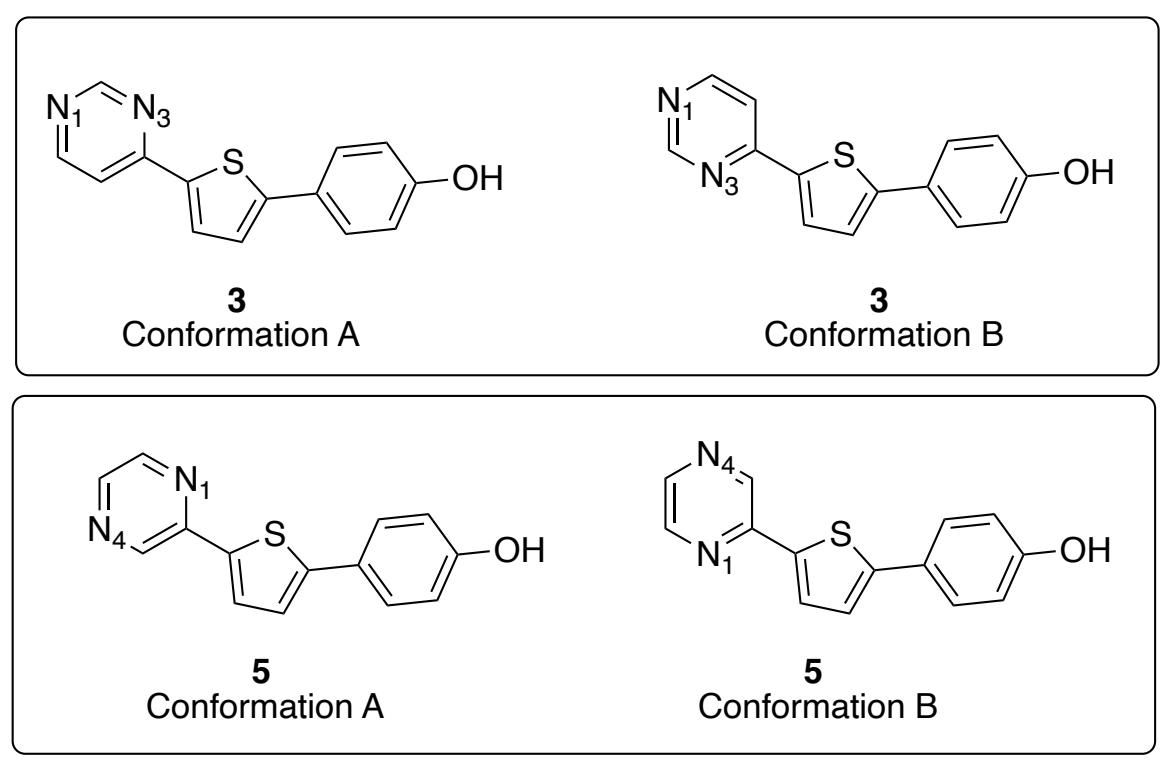

Figure 2. Nomenclature used for the protonation sites $\left(\mathrm{N}_{1}, \mathrm{~N}_{3}\right.$, and $\left.\mathrm{N}_{4}\right)$, along with $A / B$ conformations exemplified for compound $\mathbf{3}$ and $\mathbf{5}$.

The molecules of this series are not planar in their ground state. They all exhibit a 31$39^{\circ}$ dihedral angle between the phenolic group and the aromatic ring of the linker (see Figure 
3a for compound $\mathbf{3}$ and Table S2 in the Supporting Information). The frontier orbitals energies and HOMO/LUMO gaps are given in Table S3 and the orbitals are depicted in Figure S2 (Supporting Information). As expected, the HOMO and LUMO localizations are typical for push-pull systems. Whereas the HOMOs are mostly located on the donor moieties, the LUMOs primarily occupy the diazine acceptors in all molecules. Modifications in the D- $\pi$-A backbone only led to changes in the energy levels. As can be seen by comparing compounds $\mathbf{1}$ vs 2 and 3 vs 4, the LUMOs stabilize and the HOMOs destabilize as the length of the $\pi$ conjugated system increases. Overall, this results in a decrease of the HOMO-LUMO gap, which ranges from $7.74 \mathrm{eV}$ for 1 to $6.77 \mathrm{eV}$ for 4 . The presence of a pyrazine or pyrimidine ring as an acceptor moiety did not have a significant impact on the electronic structure (see for instance $\mathbf{2} v s \mathbf{7}$ or $\mathbf{3} v s \mathbf{5}$ ). In contrast, the use of a quinoxaline instead of a pyrazine unit (6 vs 5) appreciably decreased the HOMO-LUMO electronic gap (by $0.4 \mathrm{eV}$ ) due to the stabilization of the LUMO, mark of a greater acceptor character. Replacing the $\mathrm{OH}$ electron donating group of $\mathbf{3}$ with a methoxy group (3OMe) yielded almost identical electronic properties.

As a marker of the $\mathrm{D} / \mathrm{A}$ character of the molecules, the dipole moments calculated for the ground states, $\mu_{0-0}$, are presented in Table 1 . The values ranged from $2.34 \mathrm{D}$ to $6.64 \mathrm{D}$ and were highly sensitive to the position of the nitrogen atoms in the diazine unit. The use of a pyrimidine moiety in 1-4 resulted in a higher $\mu_{0-0}$ compared to those of pyrazine derivatives 57.

\subsection{Computed properties relevant to absorption for the neutral forms}

In all molecules, the most intense computed transition in DMSO was the initial $\mathrm{S}_{0} \rightarrow$ $\mathrm{S}_{1}$ excitation. The corresponding computed vertical transition energies and oscillator strengths (f) relevant to absorption are reported in Table 2. In all compounds, this excitation consists mainly in a HOMO to LUMO $\left(\pi-\pi^{*}\right)$ transition. The Natural Transitions Orbitals (NTO) ${ }^{30}$ of 
compound $\mathbf{3}$ are illustrated in Figure 3 b. They reveal that the excitation involves the whole conjugated pathway of the compound, and in turn, exhibits a large oscillator strength and a sizeable transition dipole moment $\mu_{0-1}$ (Table 1). $\mu_{0-1}$ values increase further within the series as the length of the $\pi$-conjugated pathway increases, with higher values for $\mathbf{2}, \mathbf{4}$, and $\mathbf{7}$ compared to $1,3,5$, and $\mathbf{6}$.

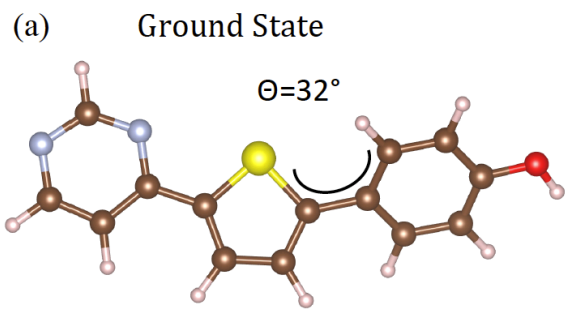

$\mathrm{BLA}=0.0081 \AA$

(b)

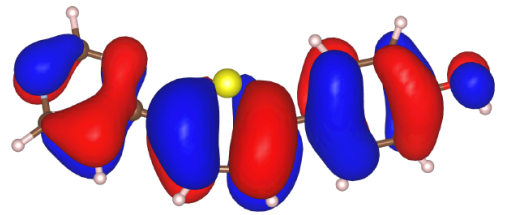

(c)

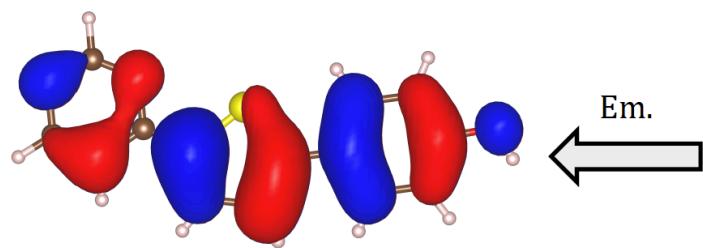

Excited State

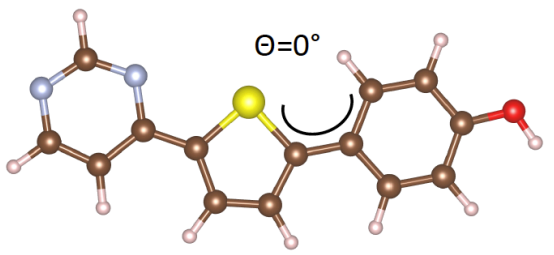

$\mathrm{BLA}=0 \AA$
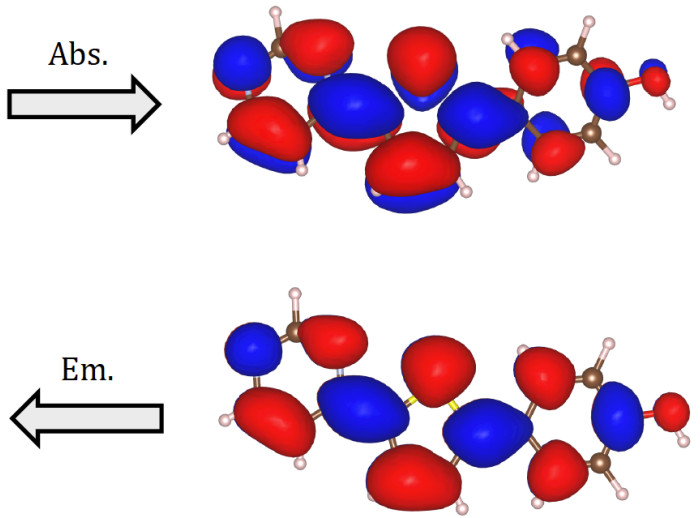

Figure 3. Geometry, dihedral angle between the linker and the phenol moiety, and BLA for neutral compound 3 (a). Natural transition orbitals for absorption (b) and emission (c) for this compound (isovalue $=0.02$ ).

Table 1. Computed dipole moments in debye (D) for the ground $\left(\mu_{0-0}\right)$ and first excited states $\left(\mu_{1-1}\right)$ of compounds 17 in their neutral form, along with the transition dipole moments relevant to absorption $\left(\mu_{0-1}\right)$ and emission $\left(\mu_{1-0}\right)$.

\begin{tabular}{ccccc}
\hline Compd & $\boldsymbol{\mu}_{\mathbf{0 - 0}}$ & $\boldsymbol{\mu}_{\mathbf{1 - 1}}$ & $\boldsymbol{\mu}_{\mathbf{0 - 1}}$ & $\boldsymbol{\mu}_{\mathbf{1 - 0}}$ \\
\hline $\mathbf{1}$ & 5.45 & 13.91 & 8.23 & 11.54 \\
$\mathbf{2}$ & 5.44 & 13.95 & 10.31 & 13.29 \\
\hline
\end{tabular}




\begin{tabular}{ccccc}
\hline $\mathbf{3}$ & 6.42 & 12.97 & 8.23 & 10.99 \\
30Me & 6.64 & 13.98 & 8.46 & 11.27 \\
$\mathbf{4}$ & 6.62 & 15.06 & 9.52 & 13.56 \\
$\mathbf{5}$ & 3.11 & 9.39 & 8.14 & 10.89 \\
$\mathbf{6}$ & 2.99 & 9.86 & 8.66 & 9.65 \\
$\mathbf{7}$ & 2.34 & 9.13 & 10.39 & 13.29 \\
\hline
\end{tabular}

Table 2. Computed properties relevant to absorption and emission for compounds 1-7 in their neutral forms derived from the $\mathrm{S}_{0} \rightarrow \mathrm{S}_{1}$ and $\mathrm{S}_{1} \rightarrow \mathrm{S}_{0}$ vertical excitations. Wavelengths and energies of the maximum of absorption and emission are presented along with the oscillator strengths, Stokes shifts, and charge transfer indexes (see SI for definition).

\begin{tabular}{cccccc}
\hline Compd & $\begin{array}{c}\lambda_{\text {abs }}[\mathbf{n m}](f) / \\
\mathbf{E}_{\text {abs }}[\mathbf{e V}]\end{array}$ & $\begin{array}{c}\mathbf{Q}_{\mathrm{CT}}(\mathbf{e}) / \\
\mathbf{D}_{\mathbf{C T}}(\mathbf{\AA})\end{array}$ & $\begin{array}{c}\lambda_{\text {em }}[\mathbf{n m}](f) / \\
\mathbf{E}_{\text {em }}[\mathbf{e V}]\end{array}$ & $\begin{array}{c}\mathbf{Q}_{\mathrm{CT}}(\mathbf{e}) / / \\
\mathbf{D}_{\mathbf{C T}}(\mathbf{\AA})\end{array}$ & Stokes shift $\left[\mathbf{c m}^{1}\right]$ \\
\hline $\mathbf{1}$ & $280(1.14) / 4.20$ & $0.56 / 3.32$ & $392(1.60) / 3.16$ & $0.51 / 3.10$ & 8355 \\
$\mathbf{2}$ & $323(1.54) / 3.83$ & $0.51 / 3.06$ & $451(1.84) / 2.75$ & $0.49 / 3.07$ & 8735 \\
$\mathbf{3}$ & $325(0.98) / 3.82$ & $0.54 / 2.79$ & $452(1.25) / 2.74$ & $0.48 / 2.46$ & 8697 \\
$\mathbf{3 O M e}$ & $326(1.03) / 3.80$ & $0.55 / 2.87$ & $456(1.31) / 2.72$ & $0.49 / 2.56$ & 8713 \\
$\mathbf{4}$ & $344(1.24) / 3.60$ & $0.53 / 3.10$ & $525(1.65) / 2.36$ & $0.49 / 2.81$ & 9959 \\
$\mathbf{5}$ & $326(0.96) / 3.81$ & $0.52 / 2.50$ & $454(1.23) / 2.73$ & $0.47 / 2.25$ & 8676 \\
$\mathbf{6}$ & $349(1.01) / 3.55$ & $0.56 / 2.70$ & $478(1.36) / 2.59$ & $0.51 / 2.57$ & 7754 \\
$\mathbf{7}$ & $318(1.60) / 3.90$ & $0.47 / 2.55$ & $448(1.85) / 2.76$ & $0.45 / 2.60$ & 8786 \\
\hline
\end{tabular}

Closely related to the evolution of the electronic gap within this series, the absorption wavelengths calculated for this transition were also mainly influenced by the extent of the $\pi$ conjugation, both in the bridge and in the diazine acceptor group. In fact, the presence of a pyrimidine or a pyrazine acceptor in these compounds did not significantly impact the computed properties (Table 2). Amongst pyrimidine and pyrazine-based molecules, the phenyl bridge in 1 led to the most blue-shifted absorption at $280 \mathrm{~nm}$. The absorption wavelength of $\mathbf{2}, \mathbf{3}, \mathbf{5}$, and $\mathbf{7}$ are in the $318-326 \mathrm{~nm}$ range, which suggests that thiophene and phenylenevinylene bridges induce similar effects in terms of $\pi$-conjugation. The 
thienylenevinylene unit in $\mathbf{4}$ further shifted the absorption at $344 \mathrm{~nm}$. Compound 6, encompassing a $\pi$-extended quinoxaline acceptor, showed the most red-shifted absorption within the series at $349 \mathrm{~nm}$, as it possesses the lowest LUMO energy level.

As already stated, during this absorption process, the electronic density remains distributed over the whole molecular $\pi$-conjugated backbone in the two states involved. The diazine and phenol moieties have a moderate accepting/donating character and, therefore, the excitation leads primarily to a $\pi-\pi^{*}$ transition with a modest ICT character. To evaluate the magnitude of the ICT upon excitation, the amount of charge transfer $\left(\mathrm{Q}_{\mathrm{CT}}\right)$ and the distance of charge transfer $\left(\mathrm{D}_{\mathrm{CT}}\right)$ can be extracted (see Supporting Information for details). ${ }^{31,32}$ The $\mathrm{Q}_{\mathrm{CT}}$ and $\mathrm{D}_{\mathrm{CT}}$ values between the two states for the series of neutral compounds are presented in Table 2. For all compounds, the transfer $\mathrm{S}_{0} \rightarrow \mathrm{S}_{1}$ was around half an electron and the $\mathrm{D}_{\mathrm{CT}}$ varied from $2.5 \AA$ to $3.3 \AA$. When compared to chromophores with high $\mathrm{CT}$ character, the $\mathrm{D}_{\mathrm{CT}}$ values remained moderate. ${ }^{31,33}$ In fact, here the molecules have relatively short D- $\pi$-A backbones, where the conjugation extends only along a few bonds. The $\mathrm{Q}_{\mathrm{CT}}$ are typical of charge transfer over such distances and show the intrinsic moderate CT character of these

excitations. ${ }^{34,35}$ Overall, the CT character is slightly more pronounced at $\mathbf{1}$, where the D and A moieties are the least coupled. Nevertheless, the changes in the CT character upon chemical modification in this series remain small. A correlation between the nature of the diazine heterocycle and the transfer distance is visible as the substitution of the pyrazine $(\mathbf{5} / 7)$ by a pyrimidine ring (3/2) increases slightly the $\mathrm{D}_{\mathrm{CT}}$ value.

\subsection{Measured absorption properties of neutral forms}

The absorption and emission spectra of compounds 2-7 and the methoxy analogue 3OMe were registered at room temperature in DMSO. This solvent was chosen for solubility reasons. The analyses were performed at low concentration of solute $\left(1.0-3.0 \times 10^{-5} \mathrm{M}\right)$. 
Normalized spectra of compounds 2-7 are displayed in Figure 4 and the data are summarized in Table 3.

All compounds exhibited a main absorption band in the UV-purple region of the spectrum, with absorption coefficients between 20.0 and $28.4 \mathrm{mM}^{-1} \mathrm{~cm}^{-1}$. For pyrazine and quinoxaline derivatives 5-7, less intense bands/shoulders of higher energy were also observed. As predicted by TD-DFT, compounds 2 and 7 showed the most blue-shifted absorption maxima, as the biphenylene vinyle linker was computed to be the least efficient $\pi$-conjugated system in the 2-7 series. The similarity in the computed absorption of pyrimidine and pyrazine analogues $\mathbf{2} / \mathbf{7}$ and $\mathbf{3 / 5}$, is also retrieved in these measured properties. This result agrees with earlier experimental structure-properties relationships established for other push-pull diazine chromophores. ${ }^{36}$ The presence of a thienylenevinylene linker in the structure of chromophore 4 prompted red shifts of $0.40 \mathrm{eV}$ and $0.26 \mathrm{eV}$ with regards to thienylene and phenylenevinylene analogues $\mathbf{2}$ and $\mathbf{3}$, respectively, also in good agreement with the predicted theoretical shifts described above. The absorption band of the quinoxaline derivative 6 was remarkably red-shifted compared to the pyrazine analogue $\mathbf{5}$, being the compound with the highest bathochromic shift in the series. Finally, as anticipated by TD-DFT calculations, compound 30Me showed similar absorption features to its phenol analogue $\mathbf{3}$, indicating a similar electron-donating strength for the methoxy and hydroxy groups although the Hammett constant values indicate that the latter is slightly stronger. ${ }^{37}$ 

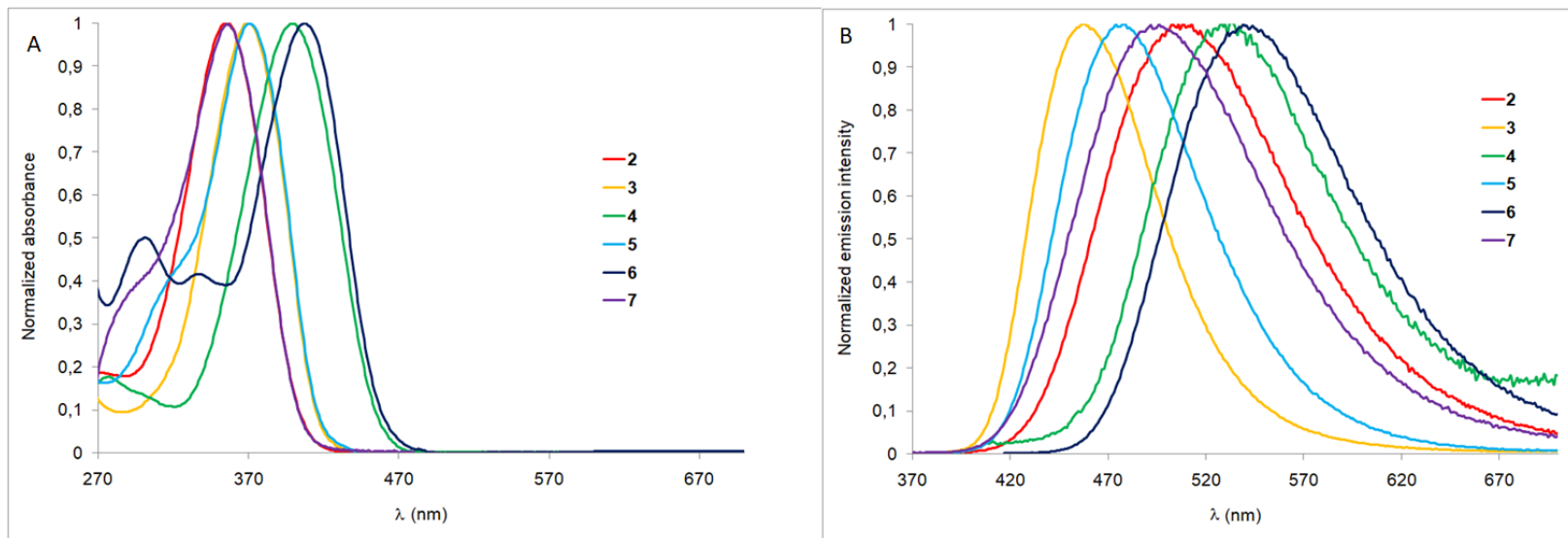

Figure 4. Normalized absorption (A) and emission (B) spectra of chromophores 2-7 in DMSO.

Table 3. Photophysical properties of neutral compounds 2-7 and 3OMe in DMSO. $\lambda_{\text {abs }}$ $\left(E_{a b s}\right)$ and $\lambda_{\mathrm{em}}\left(\mathrm{E}_{\mathrm{em}}\right)$ are respectively the wavelengths (energies) of the maximum of absorption and emission.

\begin{tabular}{cccc}
\hline Compd & $\lambda_{\text {abs }}[\mathbf{n m}],\left(\varepsilon\left[\mathbf{m M}^{-\mathbf{1}} \mathbf{c m}^{-1}\right]^{\mathbf{a}}\right) / \mathbf{E}_{\text {abs }}[\mathbf{e V}]$ & $\lambda_{\text {em }}[\mathbf{n m}]\left(\boldsymbol{\Phi}_{\mathrm{F}}\right) / \mathbf{E}_{\text {em }}[\mathbf{e V}]$ & Stokes shift $\left[\mathbf{c m}^{-\mathbf{1}}\right]$ \\
\hline $\mathbf{2}$ & $353(22.7) / 3.51$ & $506(0.54) / 2.45$ & 8550 \\
$\mathbf{3}$ & $368(20.0) / 3.37$ & $467(0.64) / 2.65$ & 5807 \\
$\mathbf{3 0 M e}$ & $365(22.7) / 3.40$ & $453(0.89) / 2.74$ & 5323 \\
$\mathbf{4}$ & $399(23.3) / 3.11$ & $530(0.031) / 2.34$ & 6211 \\
$\mathbf{5}$ & $370(25.3) / 3.35$ & $478(0.83) / 2.59$ & 6130 \\
$\mathbf{6}$ & $408(28.4) / 3.04$ & $539(0.47) / 2.30$ & 5969 \\
$\mathbf{7}$ & $365(26.4) / 3.40$ & $496(0.51) / 2.50$ & 7259 \\
\hline
\end{tabular}

a $1 \mathrm{mM}^{-1} \mathrm{~cm}^{-1}=1000 \mathrm{M}^{-1} \mathrm{~cm}^{-1}$

\subsection{Computed properties relevant to emission for the neutral forms}

Upon relaxation, all compounds of the series exhibit a nearly complete planarization in the excited state (ES), and the torsion angle between the linker and the phenol moiety vanishes (Table S2, Supporting Information). This planarization induces an increase of the conjugation accompanied by a substantial decrease of the bond length alternation (BLA) in the ES (Table S6, Supporting Information). In addition, the dipole moments of the ES $\left(\mu_{1-1}\right)$ are systematically increased for all compounds compared to those of the GS $\left(\mu_{0-0}\right)$, ranging from $9.13 \mathrm{D}$ for 7 to $15.06 \mathrm{D}$ for 4 (Table 1). Analogously to what was observed for GS, the pyrimidine derivatives present higher dipole moments in the ES $\left(\mu_{1-1}\right)$ than their pyrazine 
analogues. Electronic transitions for the ES to GS relaxation present a transition dipole moment $\left(\mu_{1-0}\right)$ and oscillator strength higher than those obtained for the excitation processes, as can be seen in Tables 1 and 2. Meanwhile, the corresponding NTO analysis reveals results similar to those observed for absorption (Figure 3c).

The computed emission wavelengths follow the same trend established above for absorption. Compounds 4, with a thienylenevinylene bridge, and $\mathbf{6}$, with a quinoxaline acceptor unit, are the most red-shifted of the series, while $\mathbf{2}, \mathbf{3}, \mathbf{5}$, and $\mathbf{7}$ emit at similar wavelengths, around $450 \mathrm{~nm}$. The charge transfer characteristics for this emission process were evaluated through $\mathrm{Q}_{\mathrm{CT}}$ and $\mathrm{D}_{\mathrm{CT}}$ (Table 2). Computed values are close to those obtained for the ground to first excited state excitation (absorption), although in general they are slightly reduced. The ES geometries are indeed more planar and, in turn, their electronic structures are more delocalized, slightly diminishing the CT character that occurs upon deexcitation (emission). Nevertheless, emission retains a clear ICT nature.

\subsection{Measured emission properties of the neutral forms}

The emission properties measured for 2-7 are summarized in Table 3. Except compound 4, all compounds are luminescent in DMSO with relatively high quantum yields $\left(\Phi_{\mathrm{F}}>0.47\right)$. The low emission of the thienylenevinylene derivative 4 is in agreement with

previous observations in pyrimidine derivatives. ${ }^{20 b, 38}$ However, to the best of our knowledge, there is no clear experimental explanation for this discrepancy. Our theoretical results presented above (Table 2) did not hint at any differences explaining this fluorescence quenching in 4 compared to other members of the series. In fact, the potential non-radiative decay mechanisms, such as those involving internal conversion (IC) or intersystem crossing (ISC), ${ }^{29,39,40}$ are out of reach for the vertical TD-DFT model used in this work. 
Pyrimidine derivative 3 exhibited the most blue-shifted emission, whereas the emission of its pyrazine analogue 5 was red-shifted by $0.06 \mathrm{eV}$. On the other hand, the emission of the pyrazine derivative 7 is hypsochromically shifted by $0.15 \mathrm{eV}$ with respect to its pyrimidine analogue $\mathbf{2}$. As predicted by TD-DFT, the presence of a vinylene linker (4 vs $\mathbf{3})$ and the replacement of a phenylene by a thienylene linker (4 vs 2) result in a significantly redshifted emission. Similarly, the quinoxaline derivative $\mathbf{6}$ showed a dramatic red-shift with regards to its non-annulated analogue $\mathbf{5}$, in agreement with our previous studies. ${ }^{35}$ As far as the electron-donating group is concerned, phenol substituted derivative $\mathbf{3}$ exhibits a moderate red-shift of $0.09 \mathrm{eV}$ compared to its methoxy analogue 30Me.

The evolution of the experimental emission wavelengths upon chemical modification is in overall good agreement with the computed values. In addition, a relevant marker of the agreement between computations and experimental measurements for absorption and emission properties is the $\mathrm{E}^{0-0}$ energy (absorption and emission crossing point). ${ }^{41}$ Under the current level of theory, the computed $\mathrm{E}^{0-0}$ energies are found to be very close to the experimental values for the whole series of compounds, with a mean squared error (MSE) of $0.06 \mathrm{eV}$ (see Supporting Information for details).

Emission measurements were also performed in toluene and $\mathrm{CH}_{2} \mathrm{Cl}_{2}$ and the results are presented in Table S11. Whereas only a slight shift of absorption band is observed when the polarity is increased, a more significant positive emission solvatochromsism, characteristic of ICT chromophores is observed. ${ }^{42}$ Stokes shifts were plotted versus the Reichardt polarity parameter (Figure S14), which is indicative of a higher solvatochromic range for the biphenylenevinylene derivatives 2 and 7, as was observed previously for other series of diazine push-pull chromophores. ${ }^{36}$

\subsection{Effect of protonation and deprotonation: computational insights}


The chromophores in this series can be protonated on one of the two nitrogen atoms of the pyrimidine/pyrazine ring, named $\mathrm{N}_{1}$ and $\mathrm{N}_{3} / \mathrm{N}_{4}$ in Figure 2. Comparing the theoretical Boltzmann populations obtained, all compounds present a clearly selective protonation site (on $\mathrm{N}_{1}$ for 1-4 and 6-7, on $\mathrm{N}_{4}$ for 5). Nevertheless, these populations correspond to an energy difference $(\Delta \mathrm{G})$ of less than $5 \mathrm{kcal} \cdot \mathrm{mol}^{-1}$ (Table 4$)$. Thus, both forms can be expected in solution at room temperature. The analyses of the electronic structure (atomic partial charges in Table S7 and electrostatic potentials isosurfaces in Figure S5, Supporting Information) show no drastic differences between the two isomers. Moreover, no differences in the ground and excited state properties are observed when comparing the two possible protonated forms (Table S8, Supporting Information). Hereafter, only theoretical results for the most stable protonation site of each molecule are presented along the text.

Table 4. Boltzmann populations at $298 \mathrm{~K}$ between the two protonation sites $\mathrm{N}_{1}$ and $\mathrm{N}_{3} / \mathrm{N}_{4}$, in $\%$, along with the $\Delta \mathrm{G}$ values for the least stable site, in $\mathrm{kcal} \cdot \mathrm{mol}^{-1}$.

\begin{tabular}{ccc}
\hline & $\mathbf{N}_{\mathbf{1}}(\mathbf{\%}(\Delta \mathbf{G}))$ & $\mathbf{N}_{\mathbf{3}} / \mathbf{N}_{\mathbf{4}}(\mathbf{\%}(\Delta \mathbf{G}))$ \\
\hline $\mathbf{1}$ & 98 & $2(2.3)$ \\
$\mathbf{2}$ & 100 & $0(3.3)$ \\
$\mathbf{3}$ & 100 & $0(5.0)$ \\
$\mathbf{3 O M e}$ & 100 & $0(4.9)$ \\
$\mathbf{4}$ & 99 & $1(2.3)$ \\
$\mathbf{5}$ & $7(1.6)$ & 93 \\
$\mathbf{6}$ & 98 & $2(2.2)$ \\
$\mathbf{7}$ & 89 & $11(1.2)$ \\
\hline
\end{tabular}

The protonation does not significantly modify the GS equilibrium geometry of the compounds, apart from a slight planarization of the backbone (Table S2, Supporting Information). For instance, the dihedral angle between the linker and the phenol group is reduced by less than $3^{\circ}$ compared to the neutral form. Nevertheless, the BLA values are reduced by half, indicating that the $\pi$ delocalization is more efficient in the GS of the 
protonated forms (see Table S6, Supporting Information). The predominant configurations and conformations previously described for the neutral compounds remain the most stable in the case of protonated forms ( $E$ over $Z$, and A over B).

Changes in the topology of the frontier molecular orbitals of the protonated molecules are negligible compared to the neutral forms, that is, the HOMO and LUMO are still highly delocalized orbitals with a more important contribution of the donor for the HOMO and the acceptor for the LUMO (Figure S3, Supporting Information). In contrast, their energy levels are very sensitive to the presence of the proton (Table S4, Supporting Information). For all molecules, both HOMO and LUMO levels are significantly stabilized by $c a .0 .2-0.3 \mathrm{eV}$ for the former and by more than $1 \mathrm{eV}$ for the latter, confirming that the diazine moiety is a stronger electron acceptor after protonation. This results in a decrease of the electronic gap of the molecules by around $0.8 \mathrm{eV}$ compared to their neutral counterparts.

Table 5. Computed properties relevant to absorption and emission for compounds 1-7 in their protonated form, derived from the $S_{0} \rightarrow S_{1}$ and $S_{1} \rightarrow S_{0}$ vertical excitations. Wavelengths and energies of the maximum of absorption and emission are presented along with the oscillator strengths, protonation shifts compared to neutral forms, and charge transfer analysis.

\begin{tabular}{|c|c|c|c|c|c|c|}
\hline Compd & $\begin{array}{c}\lambda_{\text {abs }}[\mathrm{nm}](f) / \\
\mathbf{E}_{\text {abs }}[\mathrm{eV}] \\
\end{array}$ & $\mathbf{Q}_{\mathrm{CT}}(\mathrm{e}) / \mathbf{D}_{\mathrm{CT}}(\AA)$ & $\begin{array}{c}\text { Protonation } \\
\text { shift }[\mathrm{eV}]\end{array}$ & $\begin{array}{c}\lambda_{\mathrm{em}}[\mathrm{nm}](f) / \\
\mathbf{E}_{\mathrm{em}}[\mathrm{eV}] \\
\end{array}$ & $\mathbf{Q}_{\mathrm{CT}}(\mathrm{e}) / \mathbf{D}_{\mathrm{CT}}(\AA)$ & $\begin{array}{c}\text { Protonation } \\
\text { shift }[\mathrm{eV}]\end{array}$ \\
\hline 1 & $\begin{array}{c}335(1.07) / \\
3.70\end{array}$ & $0.72 / 4.25$ & -0.50 & $\begin{array}{c}452(1.82) / \\
2.74\end{array}$ & $0.63 / 3.89$ & -0.42 \\
\hline 2 & $\begin{array}{c}375(1.51) / \\
3.31\end{array}$ & $0.65 / 4.10$ & -0.52 & $\begin{array}{c}517(1.95) / \\
2.40\end{array}$ & $0.59 / 3.82$ & -0.35 \\
\hline 3 & $\begin{array}{c}382(1.05) / \\
3.25\end{array}$ & $0.63 / 3.51$ & -0.57 & $\begin{array}{c}504(1.41) / \\
2.46\end{array}$ & $0.54 / 2.96$ & -0.28 \\
\hline 3OMe & $\begin{array}{c}385(1.10) / \\
3.22\end{array}$ & $0.65 / 3.59$ & -0.58 & $\begin{array}{c}511(1.47) / \\
2.43\end{array}$ & $0.56 / 3.04$ & -0.29 \\
\hline 4 & $\begin{array}{c}424(1.45) / \\
2.92\end{array}$ & $0.64 / 3.87$ & -0.68 & $\begin{array}{c}591(1.82) / \\
2.10\end{array}$ & $0.54 / 3.02$ & -0.26 \\
\hline 5 & $\begin{array}{c}378(0.58) / \\
3.28\end{array}$ & $0.73 / 3.78$ & -0.53 & $\begin{array}{c}509(0.91) / \\
2.43\end{array}$ & $0.67 / 3.78$ & -0.30 \\
\hline 6 & $\begin{array}{c}424(1.23) / \\
2.90\end{array}$ & $0.63 / 3.26$ & -0.65 & $\begin{array}{c}561(1.57) / \\
2.20\end{array}$ & $0.57 / 2.90$ & -0.39 \\
\hline 7 & $\begin{array}{c}376(1.51) / \\
3.30\end{array}$ & $0.63 / 4.00$ & -0.60 & $\begin{array}{c}524(1.96) / \\
2.37\end{array}$ & $0.58 / 3.74$ & -0.39 \\
\hline
\end{tabular}

These changes in the electronic structure of the GS directly impact their computed optical properties. The absorption of protonated forms of 1-7 is significantly red-shifted upon 
protonation (Table 5). The HOMO-LUMO $\pi-\pi^{*}$ transition (NTOs are depicted in Figure S9, Supporting Information) lies between $375 \mathrm{~nm}$ and $424 \mathrm{~nm}$, depending on the molecule, with a shift that ranges from $0.5 \mathrm{eV}$ for the least conjugated compound (1) to $0.68 \mathrm{eV}$ for the most conjugated compound (4), compared to the corresponding neutral forms.

The relaxed geometry of the ES (torsion angle and BLA) is roughly unchanged by the presence of the proton (see Tables S2 and S6, Supporting Information). The theoretical emission also shows a protonation-induced bathochromic shift in all cases. This shift ranges from $0.26 \mathrm{eV}$ for $\mathbf{4}$ to $0.42 \mathrm{eV}$ for $\mathbf{1}$ and is smaller than the shift computed for the absorption. This may be explained by the minor structural changes in the protonated ES compared to the geometry changes observed in the protonated GS. Noteworthy, the protonation-induced bathochromic shift of the emission follows an opposite trend within the series compared to the absorption. Namely, the least $\pi$-extended compound (1) exhibits now the most shifted emission, while the most $\pi$-extended molecule (4) is the least impacted.

The charge transfer characteristics of absorption and emission of the protonated species are detailed in Table 5. In both cases $\mathrm{Q}_{\mathrm{CT}}$ increases after protonation for all compounds, reaching a maximum value of 0.73 e upon excitation (relevant to absorption) and 0.67 e upon de-excitation (relevant to emission) for 5 . The $\mathrm{D}_{\mathrm{CT}}$ values also increase globally, ranging between $3.26 \AA$ and $4.25 \AA$ for the absorption, and between $2.90 \AA$ and $3.89 \AA$ for the emission. The charge transfer is also predicted to be more efficient during absorption than emission for the whole protonated series. The nature of the $\pi$ bridge and the acceptor moiety does not clearly correlate with the values of $\mathrm{Q}_{\mathrm{CT}}$ and $\mathrm{D}_{\mathrm{CT}}$.

Compounds 2-7 can also undergo a deprotonation on the phenolic donor group. The impact of deprotonation on the GS equilibrium geometry is the same as for protonation, inducing a planarization of the molecule with an even greater decrease of the torsion angle 
between the $\pi$ linker and the phenolate (by 8 to $10^{\circ}$ ) (Table S2, Supporting Information). Consequently, the BLA is also reduced (Table S6, Supporting Information). The most stable ground state configurations and conformations of the deprotonated species were again identical to those described for the neutral species ( $E$ over $Z$, and A over B).

Frontier molecular orbitals for the deprotonated series are depicted in Figure S4 (Supporting Information). While the LUMO remains roughly unchanged after deprotonation, the HOMO is now more clearly located on the phenolate donor moiety. Thus, the decrease in the electronic gaps within this series mainly stems from an important destabilization of the HOMO (Table S5, Supporting Information). This decrease is superior to $1 \mathrm{eV}$ for all compounds and is more pronounced than in protonation. Among all deprotonated molecules, $\mathbf{2}$ undergoes the greatest changes in the electronic properties, with a decrease in the electronic gap of $1.26 \mathrm{eV}$.

Table 6. Computed properties relevant to absorption and emission for compounds 1-7 in their deprotonated forms, derived from the $\mathrm{S}_{0} \rightarrow \mathrm{S}_{1}$ and $\mathrm{S}_{1} \rightarrow \mathrm{S}_{0}$ vertical excitations. Wavelengths and energies of the maximum of absorption and emission are presented along with the oscillator strengths, protonation shifts compared to neutral forms, and charge transfer indexes (see SI for definition).

\begin{tabular}{|c|c|c|c|c|c|c|}
\hline Compd & $\begin{array}{c}\lambda_{\text {abs }}[\mathrm{nm}](f) / \\
\mathbf{E}_{\text {abs }}[\mathrm{eV}]\end{array}$ & $\begin{array}{c}\mathbf{Q}_{\mathrm{CT}}(\mathbf{e}) / \mathbf{D}_{\mathrm{CT}} \\
(\AA)\end{array}$ & $\begin{array}{c}\text { protonation } \\
\text { shift }[\mathrm{eV}]\end{array}$ & $\begin{array}{c}\lambda_{\mathrm{em}}[\mathrm{nm}](f) / \\
\mathbf{E}_{\mathrm{em}}[\mathrm{eV}]\end{array}$ & $\begin{array}{l}\mathbf{Q}_{\text {CT }}(\mathbf{e}) / \\
\mathbf{D}_{\text {CT }}(\AA)\end{array}$ & $\begin{array}{c}\text { protonation } \\
\text { shift }[\mathrm{eV}]\end{array}$ \\
\hline 1 & $\begin{array}{c}351(1.10) / \\
3.53\end{array}$ & $0.79 / 4.62$ & -0.67 & $482(1.79) / 2.57$ & $0.67 / 4.01$ & -0.59 \\
\hline 2 & $\begin{array}{c}382(1.48) / \\
3.24\end{array}$ & $0.75 / 5.18$ & -0.59 & $570(2.15) / 2.17$ & $0.69 / 4.56$ & -0.58 \\
\hline 3 & $\begin{array}{c}404(1.05) / \\
3.07\end{array}$ & $0.72 / 4.10$ & -0.75 & $551(1.47) / 2.25$ & $0.60 / 3.20$ & -0.49 \\
\hline 4 & $\begin{array}{c}430(1.39) / \\
2.88\end{array}$ & $0.62 / 3.73$ & -0.72 & $660(1.87) / 1.89$ & $0.62 / 3.73$ & -0.47 \\
\hline 5 & $\begin{array}{c}394(1.03) / \\
3.15\end{array}$ & $0.70 / 4.07$ & -0.66 & $549(1.43) / 2.26$ & $0.60 / 3.30$ & -0.47 \\
\hline 6 & $\begin{array}{c}424(1.12) / \\
2.92\end{array}$ & $0.76 / 4.40$ & -0.63 & $591(1.56) / 2.10$ & $0.65 / 3.68$ & -0.49 \\
\hline 7 & $\begin{array}{c}372(1.52) / \\
3.34\end{array}$ & $0.72 / 4.97$ & -0.56 & $550(2.15) / 2.25$ & $0.67 / 4.54$ & -0.51 \\
\hline
\end{tabular}

The relaxed geometry of the ES is also significantly modified by the deprotonation. In this case, the torsion angle between linker and donor is further reduced compared to the ES of 
the neutral and protonated forms (Table S2, Supporting Information). In addition, the computed BLAs for deprotonated species show for all compounds a negative value in the ES, higher in absolute value (except for $\mathbf{1}$ and 7) than in the GS, which suggests a reduced delocalization of the electron density (Table S6, Supporting Information).

As a result of these structural and electronic modifications, the deprotonation also induces a bathochromic shift of both the absorption and the emission (NTOs for the $\pi-\pi^{*}$ transition are presented in Figure S9, Supporting Information). This shift is found to be higher than that predicted for the protonated series. The shift in the absorption ranges from $0.56 \mathrm{eV}$ for 7 to $0.75 \mathrm{eV}$ for $\mathbf{3}$, for which the computed transition now peaks at $430 \mathrm{~nm}$. The emission is calculated above $550 \mathrm{~nm}$ for most compounds. The transition shifts up to $660 \mathrm{~nm}$ for 4 ( $0.47 \mathrm{eV}$ shift), although compound $\mathbf{1}$ is the most affected compared to its neutral counterpart (0.59 eV shift), as was also the case in protonation.

Along with this greater absorption/emission shift upon deprotonation, the charge transfer during the transition is also found to be higher within the deprotonated series, i.e., both $\mathrm{Q}_{\mathrm{CT}}$ and $\mathrm{D}_{\mathrm{CT}}$ values are greater than those computed for the neutral or protonated forms (Table 6). Interestingly, the charge transfer for emission is still very important although less than for the absorption, with a $\mathrm{Q}_{\mathrm{CT}}$ between 0.6 and $0.7 \mathrm{e}$ and a $\mathrm{D}_{\mathrm{CT}}$ around $4 \AA$.

\subsection{Effect of protonation and deprotonation: experimental results}

The sensitivity of the photophysical properties of compounds 2-7 and 3OMe to the acidic and basic medium was studied by using $10^{-1} \mathrm{M}$ solutions of camphorsulphonic acid (CSA) and 1,8-diazabicyclo[5.4.0]undec-7-ene (DBU), respectively. The photophysical properties of protonated and deprotonated species are summarized in Table 7. Even for this high concentration of acid $\left(10^{-1} \mathrm{M}\right.$ corresponds to more than 1000 equivalents), it was not possible to fully protonate the pyrimidine derivatives 2-4 and 3OMe. This fact agrees with previous observations indicating that push-pull diazine derivatives with extended $\pi$ - 
conjugated linkers are more difficult to protonate than analogue push-pull structures with a shorter $\pi$-bridge. ${ }^{43}$ For pyrazine and quinoxaline derivatives 5-7, there was no sign of protonation in $10^{-1} \mathrm{M}$ solutions of CSA or trifluoroacetic acid. This fact is consistent with the lower basicity of these heterocycles with respect to pyrimidine (pyrimidine: $\mathrm{pKa} \sim 1.3$; pyrazine: $\mathrm{pKa} \sim 0.65$; quixoxaline: $\mathrm{pKa} \sim 0.56),{ }^{44}$ although in contradiction with that observed for other pyrazine- and quinoxaline-based push-pull structures with shorter conjugated bridges. ${ }^{20 \mathrm{~b}, 45}$ The protonation of pyrimidine derivatives $\mathbf{2 - 4}$ and 3OMe resulted in red-shifted bands by ca. $0.5 \mathrm{eV}$, in close agreement with the computed shifts detailed above.

Table 7. Photophysical properties of protonated and deprotonated compounds 2-7 in DMSO. $\lambda_{\text {abs }}\left(E_{\mathrm{abs}}\right)$ and $\lambda_{\mathrm{em}}\left(\mathrm{E}_{\mathrm{em}}\right)$ are respectively the wavelengths (energies) of the maximum of absorption and emission.

\begin{tabular}{|c|c|c|c|c|c|c|}
\hline \multirow{2}{*}{ Compd } & \multicolumn{2}{|c|}{$\lambda_{\text {abs }}[\mathrm{nm}] / \mathbf{E}_{\mathrm{abs}}[\mathrm{eV}]$} & \multicolumn{2}{|c|}{$\lambda_{\mathrm{em}}[\mathrm{nm}]\left(\boldsymbol{\Phi}_{\mathrm{F}}\right) / \mathbf{E}_{\mathrm{em}}[\mathrm{eV}]$} & \multicolumn{2}{|c|}{ Stokes shifts $\left[\mathrm{cm}^{-1}\right]$} \\
\hline & Protonated & Deprotonated & Protonated & Deprotonated & Protonated & Deprotonated \\
\hline 2 & $417 / 2.97$ & $481 / 2.58$ & $-{ }^{a}$ & $-^{a}$ & $-{ }^{a}$ & $-^{a}$ \\
\hline 3 & $433 / 2.86$ & $487 / 2.55$ & $571(0.094) / 2.17$ & $630(0.32) / 1.97$ & 5581 & 4660 \\
\hline 30Me & $423 / 2.93$ & $-^{c}$ & $549(0.35) / 2.26$ & $-^{c}$ & 5482 & $-^{c}$ \\
\hline 4 & $467 / 2.65$ & $541 / 2.29$ & $646(0.040) / 1.92$ & $725(0.082) / 1.71$ & 5933 & 4691 \\
\hline 5 & $-b$ & $481 / 2.58$ & $-b$ & $-{ }^{a}$ & $-b$ & $-^{a}$ \\
\hline 6 & $-^{b}$ & $545 / 2.27$ & $-^{b}$ & $-^{a}$ & ${ }_{-b}^{b}$ & $-^{a}$ \\
\hline 7 & $-^{b}$ & $460 / 2.70$ & $-{ }^{b}$ & $-^{a}$ & $-{ }^{b}$ & $-^{a}$ \\
\hline
\end{tabular}

Compounds 2-7 could only be partially deprotonated in a $10^{-1} \mathrm{M}$ solution DBU. The deprotonation caused a red-shift of the absorption bands, which is again explained by the increase in ICT. The absorption bands of the deprotonated species are significantly more bathochromically shifted than those of the protonated species, as predicted with TD-DFT.

Although the complete protonation/deprotonation of the chromophores was unsuccessful, it was possible to register the emission spectra of the protonated/deprotonated species when the excitation was performed at a wavelength at which the neutral species did not absorb (i.e., at the absorption maxima of the acid and basic forms). Regarding the 
protonated forms, emission was observed for compounds 3, 4, and 30Me with red shifts of $0.42-0.48 \mathrm{eV}$ compared to the neutral forms. As predicted by calculations, these shifts were slightly lower compared to those for absorption. Moreover, quantum yields decreased significantly for chromophores 3 and 30Me. On the other hand, unlike to its methoxy analogue, ${ }^{20 \mathrm{~b}}$ the protonation of 2 induced a full quenching of the emission. As for the deprotonated forms, only the chromophores 3 and $\mathbf{4}$ were emissive. As shown in Figure 5 for compound $\mathbf{3}$, the emission of the deprotonated form was significantly more red-shifted than that of the protonated form (by $0.68 \mathrm{eV} v s 0.48 \mathrm{eV}$ ), consistently with the above theoretical predictions.

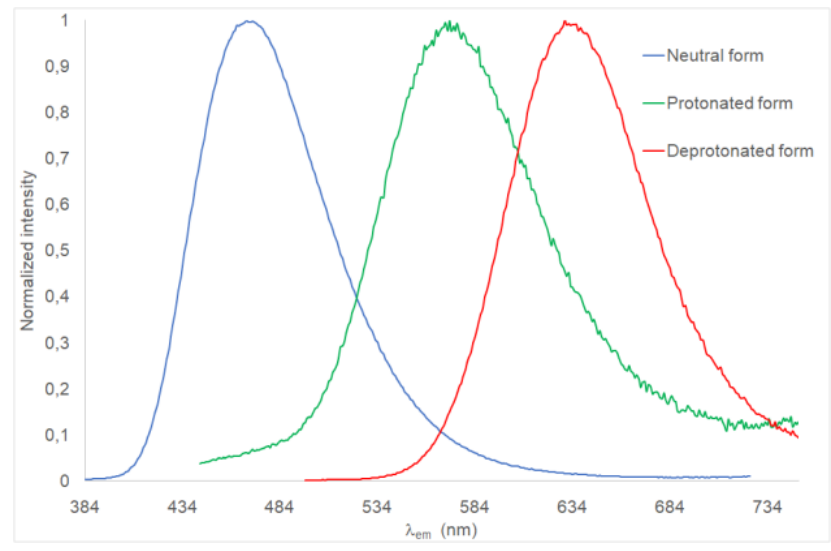

Figure 5. Normalized emission spectra in DMSO for the neutral $\left(\lambda_{\mathrm{exc}}=368 \mathrm{~nm}\right)$, protonated $\left(\lambda_{\mathrm{exc}}=433 \mathrm{~nm}\right.$ in the presence of $\left.10^{-1} \mathrm{M} \mathrm{CSA}\right)$, and deprotonated $\left(\lambda_{\mathrm{exc}}=487 \mathrm{~nm}\right.$ in the presence of $\left.10^{-1} \mathrm{M} \mathrm{DBU}\right)$ forms of compound $\mathbf{3}$.

The changes observed in the UV-vis and emission spectra of $\mathbf{3}$ upon addition of CSA and DBU are illustrated in Figures 6 and 7, respectively. In both cases, an excitation wavelength at which both neutral and (de)protonated forms absorb significantly was selected ( $\lambda_{\mathrm{exc}}=400$ and $420 \mathrm{~nm}$ for figures 6 and 7 respectively). The spectra show the progressive attenuation of the absorption/emission band stemming from the neutral species on increasing the concentration of acid/base, whereas a red-shifted band corresponding to the (de)protonated species appears. Isosbestic and isoemissive points could be observed. The 2D 
fluorescence maps of 3 in a $5 \times 10^{-2} \mathrm{M}$ solution of CSA and a $10^{-1} \mathrm{M}$ solution of DBU in DMSO clearly indicate that the dual emission corresponds to the emission of both neutral and (de)protonated species (Figures S10 and S11, Supporting Information). The intensity of both bands can be tuned by changing the excitation wavelength (Figures S12 and S13, Supporting Information). As illustrated in Figure 8, the progressive addition of DBU to a solution of $\mathbf{3}$ in DMSO prompted an emission color change from blue to white (after 1500 equivalents), and finally red (after 6700 equivalents).
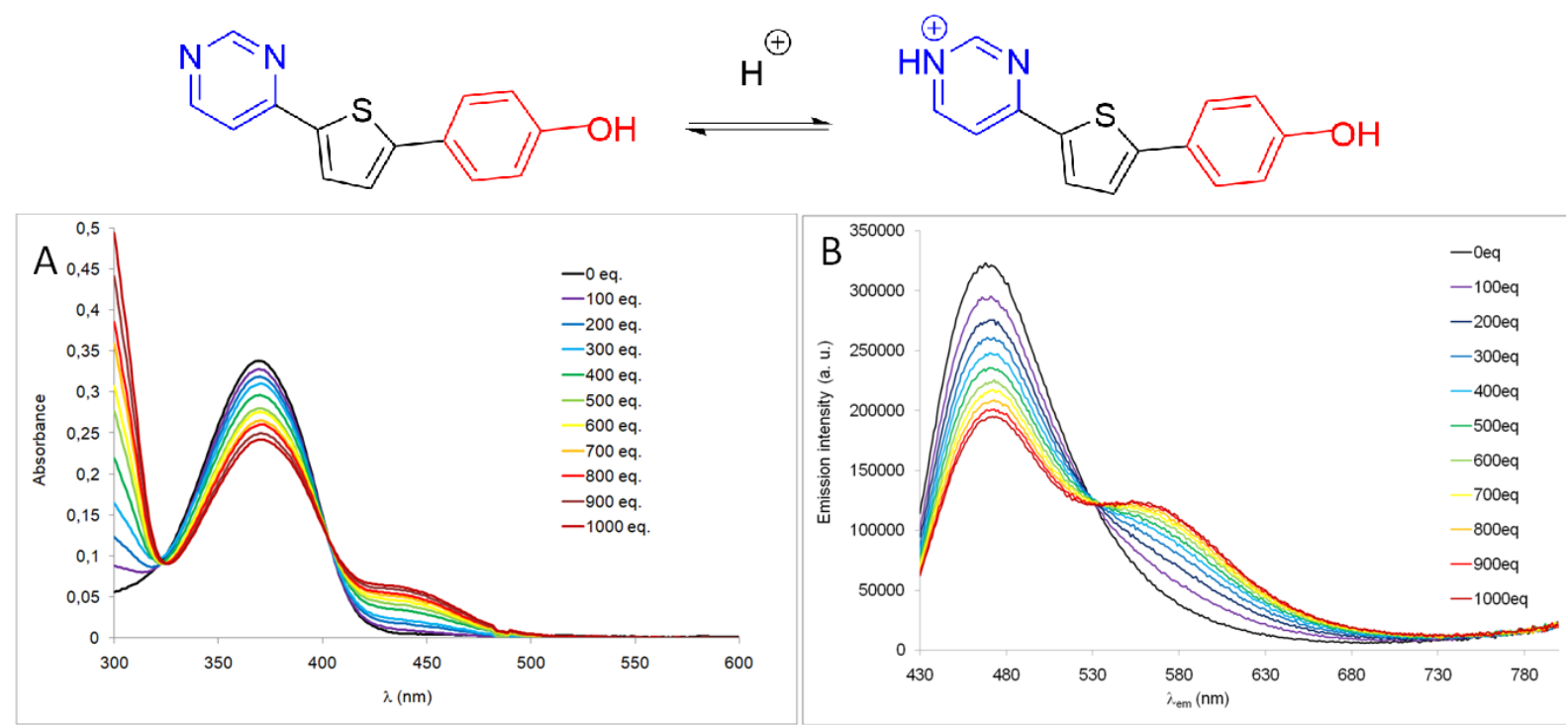

Figure 6. Changes in absorption (A) and emission $\left(B, \lambda_{\mathrm{exc}}=420 \mathrm{~nm}\right)$ spectra of a DMSO solution of $\mathbf{3}$ upon addition of CSA. 


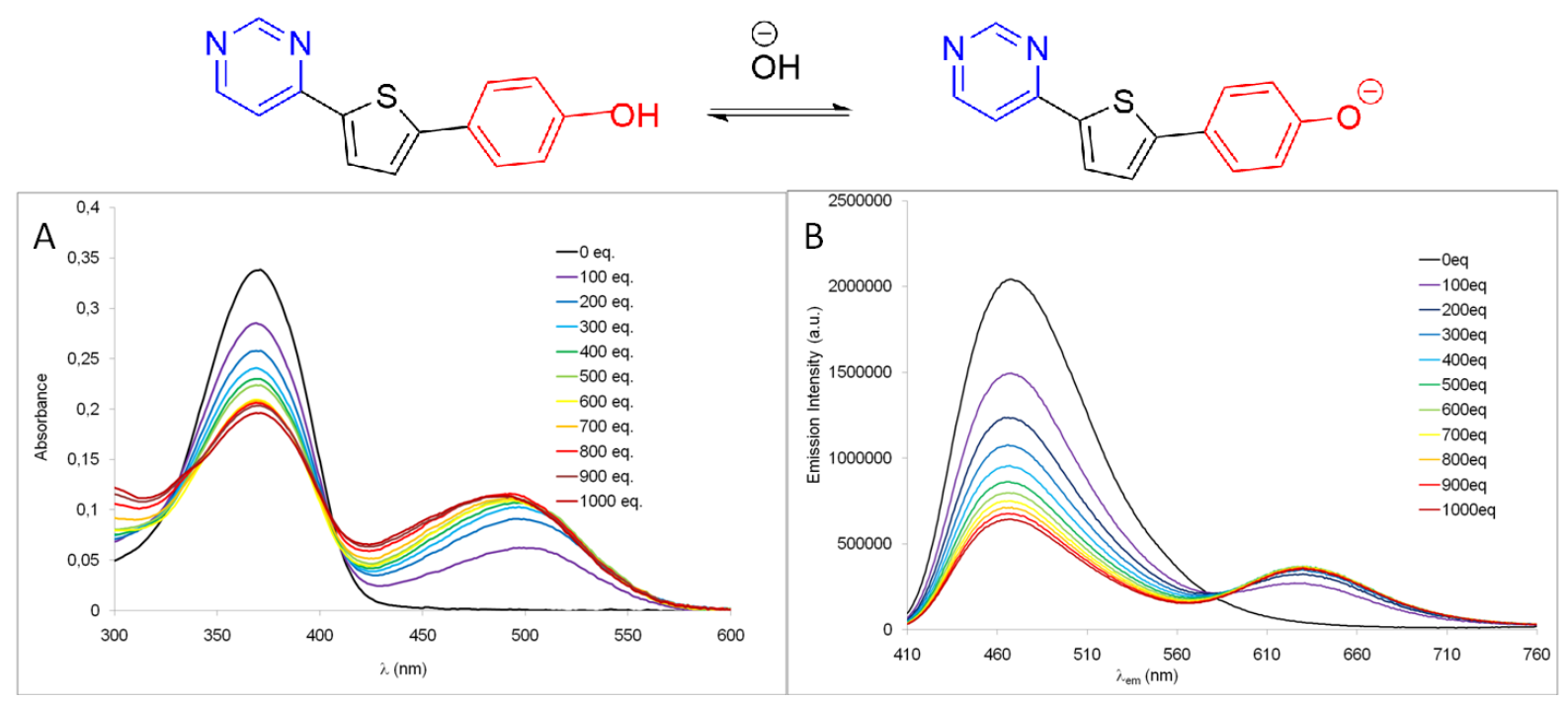

Figure 7. Changes in absorption (A) and emission (B, $\left.\lambda_{\mathrm{exc}}=400 \mathrm{~nm}\right)$ spectra of a DMSO solution of $\mathbf{3}$ upon addition of DBU.

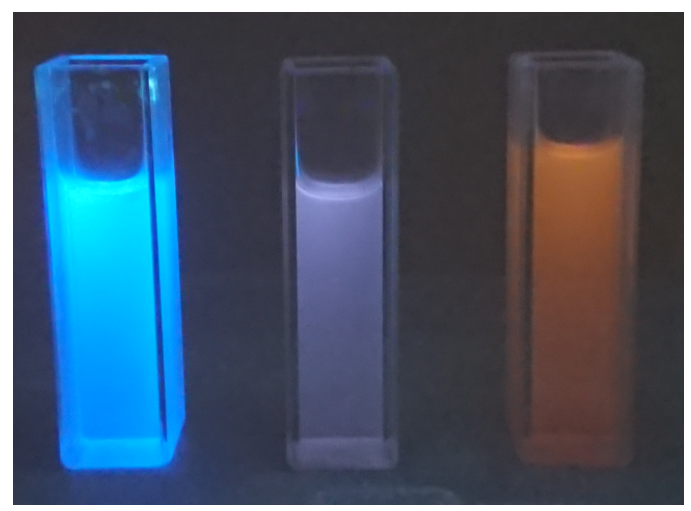

Figure 8. Changes in the color of a DMSO solution of $3\left(c=1.510^{-5} \mathrm{M}\right)$ after the addition of 1500 equivalents (middle) and 6700 equivalents (right) of DBU. Photographs were taken in the dark upon irradiation with a hand-held UV lamp $\left(\lambda_{\mathrm{exc}}=366 \mathrm{~nm}\right)$.

\section{CONCLUSION}

In this contribution, a new series of push-pull chromophores with a diazine ring (acceptor) linked to a phenolic unit (donor) through various $\pi$-conjugated bridges is proposed. The protonation (deprotonation) of the diazine (phenol) causes a red-shift of the emission. According to TD-DFT rationalizations, this shift is mainly due to an increased acceptor character of the diazine (or increased donor character of the phenol), which results in a higher charge transfer character of the bright transition. These changes are more pronounced for 
deprotonation. Throughout the whole series of molecules, the TD-DFT framework used here was able to quantitatively predict the influence of protonation/deprotonation and the effect of changes in the nature of diazine ring and $\pi$ bridge. Both protonation and deprotonation are efficient ways to attain a mixture of complementary emitting species, ultimately granting access to white light. In particular, chromophores $\mathbf{3}$ and $\mathbf{4}$, built on a pyrimidine acceptor and a thiophene/thienylenevinylene bridge, showed non-negligible emission quantum yields in solution, both in the protonated and in the deprotonated forms, paving the way towards innovative and versatile routes to design WOLED devices. 


\section{EXPERIMENTAL PART}

\subsection{General information}

All solvents were reagent grade for synthesis and spectroscopic grade for photophysical measurements. Starting materials were purchased from Sigma-Aldrich or TCI and were used without further purification. NMR spectra were recorded in $\mathrm{CDCl}_{3}$ on a Bruker Avance Neo 500 or Bruker AC-300 spectrometers. The chemical shifts $\delta$ are reported in ppm and are referenced to the appropriate solvent signals of $\mathrm{CDCl}_{3}\left({ }^{1} \mathrm{H}, \delta=7.27 \mathrm{ppm} ;{ }^{13} \mathrm{C}, \delta=\right.$ $77.0 \mathrm{ppm})$ or DMSO-d ${ }_{6}\left({ }^{1} \mathrm{H}, \delta=2.50 \mathrm{ppm} ;{ }^{13} \mathrm{C}, \delta=39.5 \mathrm{ppm}\right)$. The coupling constants $J$ are given in $\mathrm{Hz}$. In the ${ }^{1} \mathrm{H}$ NMR spectra, the following abbreviations are used to describe the peak patterns: s (singlet), d (doublet), t (triplet), q (quadruplet), m (multiplet). Acidic impurities in $\mathrm{CDCl}_{3}$ were removed by treatment with solid $\mathrm{K}_{2} \mathrm{CO}_{3}$. High-resolution mass analyses were carried out at the 'Centre Régional de Mesures Physiques de l'Ouest' (CRMPO, Université de Rennes 1) using a Bruker MicroTOF-Q II instrument. Melting points were measured on a Kofler hot stage. IR spectra were recorded on a Perkin-Elmer Spectrum 100 spectrometer. UV-visible and fluorescence spectroscopy studies in solution were conducted on a Spex Fluoromax-3 Jobin-Yvon Horiba spectrofluorometer. All solutions were measured with optical densities below 0.1 . Fluorescence quantum yields $(\sim 10 \%)$ were determined relative to 9,10-bis(phenylethynyl)anthracene in cyclohexane $\left(\Phi_{\mathrm{F}}=1.00\right) .{ }^{46}$

\subsection{Computational details}

Calculations were conducted with the Gaussian 16 program $^{47}$ with default convergence criteria. In all calculation steps the range corrected hybrid functional $\omega \mathrm{B} 97 \mathrm{X}-\mathrm{D}^{48}$ combined with a triple- $\zeta 6-311+\mathrm{G}(\mathrm{d}, \mathrm{p})$ basis set was used, and solvent effects were included through the Polarizable Continuum Model (PCM) in the Linear Response (LR) formalism. ${ }^{27}$ DFT geometry optimizations were conducted to obtain the ground-state equilibrium geometry of the molecules, along with vibrational frequency calculations to ensure that these structures 
correspond to an energy minimum. Time Dependent DFT (TD-DFT) was used to obtain the vertical electronic transition from the ground-state (absorption) and to optimize the excited states geometry (emission). For the sake of comparison, those calculations were also conducted with a PBE0 global hybrid functional ${ }^{49}$ and with a State Specific PCM approach $(\mathrm{SS}-\mathrm{PCM})^{26}$ to validate our computational procedure. This comparison is detailed in the Supporting Information.

\subsection{Synthesis of bromo derivatives}

2-(5-Bromothiophen-2-yl)pyrazine. A solution of $N$-bromosuccinimide (266 mg, $1.4 \mathrm{mmol}$ ) in DMF (3 mL) was added portionwise to a solution of thiophen-2-ylpyrazine ${ }^{50}(162 \mathrm{mg}, 1$ mmol) in DMF (3 mL). The mixture was stirred at $80{ }^{\circ} \mathrm{C}$ for $6 \mathrm{~h}$. After cooling, it was diluted with water $(50 \mathrm{~mL})$ and extracted with EtOAc $(5 \times 10 \mathrm{~mL})$. The combined organic layers were dried $\left(\mathrm{MgSO}_{4}\right)$ and concentrated under vacuum. The crude product was purified by crystallization from $\mathrm{CH}_{2} \mathrm{Cl}_{2} / n$-heptane. Cream solid. 65\% (157 mg). ${ }^{1} \mathrm{H}$ NMR (300 MHz, $\left.\mathrm{CDCl}_{3}\right) \delta: 7.12(\mathrm{~d}, 1 \mathrm{H}, J=3.9 \mathrm{~Hz}), 7.43(\mathrm{~d}, 1 \mathrm{H}, J=3.9 \mathrm{~Hz}), 8.43(\mathrm{~d}, 1 \mathrm{H}, J=2.7 \mathrm{~Hz}), 8.48$ $\left(\mathrm{dd}, 1 \mathrm{H}, J_{l}=2.7 \mathrm{~Hz}, J_{2}=1.5 \mathrm{~Hz}\right), 8.89(\mathrm{~d}, 1 \mathrm{H}, J=1.5 \mathrm{~Hz}) .{ }^{13} \mathrm{C}$ NMR $\left(75 \mathrm{MHz}, \mathrm{CDCl}_{3}\right) \delta$ : $116.7,125.8,131.3,140.0,142.7,144.0,147.7,170.3$.

2-(5-Bromothiophen-2-yl)quinoxaline. This compound was prepared from 2-(thiophen-2yl)quinoxaline ${ }^{51}(212 \mathrm{mg}, 1 \mathrm{mmol})$ following the same procedure described above. Cream

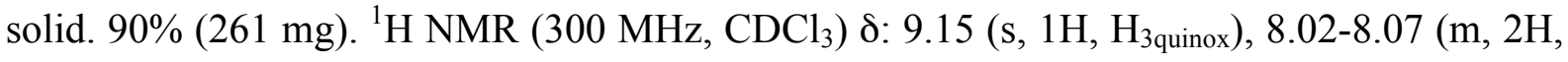
$\left.\mathrm{H}_{\text {quinox }}\right), 7.68-7.78\left(\mathrm{~m}, 2 \mathrm{H}, \mathrm{H}_{\text {quinox }}\right), 7.58\left(\mathrm{~d}, J=3.9 \mathrm{~Hz}, 1 \mathrm{H}, \mathrm{H}_{\mathrm{Th}}\right), 7.15(\mathrm{~d}, J=3.9 \mathrm{~Hz}, 1 \mathrm{H}$, $\left.\mathrm{H}_{\mathrm{Th}}\right) .{ }^{13} \mathrm{C} \mathrm{NMR}\left(75 \mathrm{MHz}, \mathrm{CDCl}_{3}\right.$ ) $\delta: 146.5,143.9,142.1,141.4,141.2,131.3,130.6,129.4$, $129.2,129.1,126.9,117.8$.

\subsection{General procedure for Suzuki-Miyaura cross-coupling reactions}

A solution of the appropriate bromo derivative $(1 \mathrm{mmol})$ and 4-hydroxyphenylboronic acid pinacol ester $(330 \mathrm{mg}, 1.5 \mathrm{mmol})$ in a mixture of toluene $(20 \mathrm{~mL}), \mathrm{EtOH}(1 \mathrm{~mL})$ and $1 \mathrm{M}$ 
aqueous $\mathrm{Na}_{2} \mathrm{CO}_{3}(1 \mathrm{~mL})$ was degassed by bubbling $\mathrm{N}_{2}$ for $10 \mathrm{~min} . \mathrm{Pd}\left(\mathrm{PPh}_{3}\right)_{4}(57 \mathrm{mg}, 0.05$ mmol) was added and the reaction mixture was stirred in a pressure tube at reflux for $15 \mathrm{~h}$. After cooling, it was diluted with water and extracted with EtOAc $(\times 3)$. The combined organic layers were dried $\left(\mathrm{MgSO}_{4}\right)$, filtered through a short pad of Celite, and concentrated under vacuum. The crude product was purified by crystallization from $\mathrm{CH}_{2} \mathrm{Cl}_{2} / n$-heptane.

(E)-4-(2-(4'-Hydroxy-[1,1'-biphenyl]-4-yl)vinyl)pyrimidine (2). Obtained from (E)-4-(4bromostyryl)pyrimidine ${ }^{43}$ (261 mg, $\left.1 \mathrm{mmol}\right)$. Pale yellow solid. 68\% (186 mg). m.p. : $206^{\circ} \mathrm{C}$ (dec.). IR (KBr) v: $3113(\mathrm{O}-\mathrm{H}), 1621(\mathrm{C}=\mathrm{C}), 1584(\mathrm{C}=\mathrm{C}), 1497(\mathrm{C}=\mathrm{C}), 1459(\mathrm{C}=\mathrm{C}), 1191(\mathrm{C}-$ O) $\mathrm{cm}^{-1} .{ }^{1} \mathrm{H}$ NMR (500 MHz, DMSO-d 6 ) $\delta: 9.64(\mathrm{~s}, 1 \mathrm{H}, \mathrm{OH}), 9.13\left(\mathrm{~s}, 1 \mathrm{H}, \mathrm{H} 2_{\mathrm{pyr}}\right) 8.76(\mathrm{~d}, 1 \mathrm{H}$, $\left.J=5.0 \mathrm{~Hz}, \mathrm{H} 6_{\text {pyr }}\right), 7.96(\mathrm{~d}, 1 \mathrm{H}, J=16.0 \mathrm{~Hz} \mathrm{H}$ vinyl $), 7.76\left(\mathrm{~d}, 2 \mathrm{H}, J=8.5 \mathrm{~Hz}, \mathrm{H}_{\mathrm{Ph}}\right), 7.67$ (d, 2H, $\left.J=8.5 \mathrm{~Hz}, \mathrm{H}_{\mathrm{Ph}}\right), 7.63\left(\mathrm{~d}, 1 \mathrm{H}, J=5.0 \mathrm{~Hz}, \mathrm{H} 5_{\mathrm{pyr}}\right), 7.57\left(\mathrm{~d}, 2 \mathrm{H}, J=8.5 \mathrm{~Hz}, \mathrm{H}_{\mathrm{Ph}}\right), 7.32(\mathrm{~d}, 1 \mathrm{H}, J$ $\left.=16.0 \mathrm{~Hz}, \mathrm{H}_{\text {vinyl }}\right), 6.86 \mathrm{ppm}\left(\mathrm{d}, 2 \mathrm{H}, J=8.5 \mathrm{~Hz}, \mathrm{H}_{\mathrm{Ph}}\right) .{ }^{13} \mathrm{C} \mathrm{NMR}\left(125 \mathrm{MHz}, \mathrm{DMSO}-\mathrm{d}_{6}\right) \delta:$ $115.8,119.1,125.2,126.2,127.8,128.4,130.0,133.4,136.6,141.1,157.46,157.53,158.3$, 161.9. HRMS (ESI/ASAP) $m / z$ : calculated for $\mathrm{C}_{18} \mathrm{H}_{15} \mathrm{~N}_{2} \mathrm{O}[\mathrm{M}+\mathrm{H}]^{+} 275.1179$, found 275.1180 . 4-(5-(4-Hydroxyphenyl)thiophen-2-yl)pyrimidine (3). Obtained from 4-(5-bromothiophen-2yl)pyrimidine ${ }^{52}$ (241 mg, $\left.1 \mathrm{mmol}\right)$. Pale yellow solid. 52\% (132 mg). m.p. > 250 ${ }^{\circ} \mathrm{C}$. IR (KBr) v: $3013(\mathrm{OH}), 1583(\mathrm{C}=\mathrm{C}), 1440(\mathrm{C}=\mathrm{C}), 1280(\mathrm{C}=\mathrm{N}), 1254(\mathrm{C}=\mathrm{N}), 1178(\mathrm{C}-\mathrm{O}) \mathrm{cm}^{-1} \cdot{ }^{1} \mathrm{H}$ NMR (500 MHz, DMSO-d 6 ) $: 9.05$ (d, 1H, $\left.J=1.0 \mathrm{~Hz}, \mathrm{H} 2_{\mathrm{pyr}}\right) 8.73$ (d, 1H, $J=5.5 \mathrm{~Hz}, \mathrm{H} 6_{\text {pyr }}$ ), $8.02\left(\mathrm{~d}, 1 \mathrm{H}, J=4.0 \mathrm{~Hz} \mathrm{H} \mathrm{H}_{\mathrm{Th}}\right), 7.95\left(\mathrm{dd}, 1 \mathrm{H}, J_{I}=5.5 \mathrm{~Hz}, J_{2}=1.0 \mathrm{~Hz}, \mathrm{H} 5_{\mathrm{pyr}}\right), 7.55(\mathrm{~d}, 2 \mathrm{H}, J=$ $\left.8.5 \mathrm{~Hz}, \mathrm{H}_{\mathrm{Ph}}\right), 7.43\left(\mathrm{~d}, 1 \mathrm{H}, J=4.0 \mathrm{~Hz}, \mathrm{H}_{\mathrm{Th}}\right), 6.80\left(\mathrm{~d}, 2 \mathrm{H}, J=9.0 \mathrm{~Hz}, \mathrm{H}_{\mathrm{Ph}}\right) .{ }^{13} \mathrm{CNMR}(125 \mathrm{MHz}$, DMSO-d $\left._{6}\right) \delta: 159.7,158.7,158.1,157.2,149.4,138.2,130.3,127.1,123.15,123.07,116.3$, 114.9. HRMS (ESI/ASAP) $m / z$ : calculated for $\mathrm{C}_{14} \mathrm{H}_{11} \mathrm{~N}_{2} \mathrm{OS}[\mathrm{M}+\mathrm{H}]^{+}$255.0587, found 255.0587.

(E)-4-(2-(5-(4-Hydroxyphenyl)thiophen-2-yl)vinyl)pyrimidine (4). Obtained from (E)-4-(2(5-bromothiophen-2-yl)-vinyl)-pyrimidine ${ }^{53}$ (267 mg, $1 \mathrm{mmol}$ ). Pale yellow solid. 58\% (162 
mg). m.p.: $220^{\circ} \mathrm{C}$ (dec.). IR (KBr) v: $3210(\mathrm{O}-\mathrm{H}), 1576(\mathrm{C}=\mathrm{C}), 1435(\mathrm{C}=\mathrm{C}), 1280(\mathrm{C}-\mathrm{O}) \mathrm{cm}^{-}$ 1. ${ }^{1} \mathrm{H}$ NMR (500 MHz, DMSO-d 6 ) $\delta: 9.07\left(\mathrm{~d}, 1 \mathrm{H}, J=1.0 \mathrm{~Hz}, \mathrm{H} 2_{\mathrm{pyr}}\right), 8.70(\mathrm{~d}, 1 \mathrm{H}, J=5.0 \mathrm{~Hz}$, H6 $\left.6_{\text {pyr }}\right), 8.07\left(\mathrm{~d}, 1 \mathrm{H}, J=15.5 \mathrm{~Hz} \mathrm{H}_{\text {vinyl }}\right), 7.56\left(\mathrm{dd}, 1 \mathrm{H}, J_{1}=5.0 \mathrm{~Hz}, J_{2}=0.9 \mathrm{~Hz}, \mathrm{H} 5_{\text {pyr }}\right), 7.51(\mathrm{~d}$, $\left.2 \mathrm{H}, J=8.5 \mathrm{~Hz}, \mathrm{H}_{\mathrm{Ph}}\right), 7.41\left(\mathrm{~d}, 1 \mathrm{H}, J=2.4 \mathrm{~Hz}, \mathrm{H}_{\mathrm{Th}}\right), 7.34\left(\mathrm{~d}, 1 \mathrm{H}, J=2.4 \mathrm{~Hz}, \mathrm{H}_{\mathrm{Th}}\right), 6.89(\mathrm{~d}, 1 \mathrm{H}$, $\left.J=15.5 \mathrm{~Hz}, \mathrm{H}_{\text {vinyl }}\right), 6.81\left(\mathrm{~d}, 2 \mathrm{H}, J=9.0 \mathrm{~Hz}, \mathrm{H}_{\mathrm{Ph}}\right) .{ }^{13} \mathrm{C}$ NMR $\left(125 \mathrm{MHz}, \mathrm{DMSO}-\mathrm{d}_{6}\right) \delta: 161.4$, $158.6,158.4,157.6,146.2,138.1,132.3,129.9,127.0,123.8,123.6,122.8,118.8,116.1$. HRMS (ESI/ASAP) $m / z$ : calculated for $\mathrm{C}_{16} \mathrm{H}_{13} \mathrm{~N}_{2} \mathrm{OS}[\mathrm{M}+\mathrm{H}]^{+}$281.0743, found 281.0748.

2-(5-(4-Hydroxyphenyl)thiophen-2-yl)pyrazine (5). Obtained from 2-(5-bromothiophen-2yl)pyrazine (241 mg, $1 \mathrm{mmol})$. Pale yellow solid. 81\% (206 mg). m.p. $>250^{\circ} \mathrm{C}$. IR (KBr) v: $3015(\mathrm{OH}), 1438(\mathrm{C}=\mathrm{C}), 1271(\mathrm{C}=\mathrm{N}), 1245(\mathrm{C}=\mathrm{N}), 1137(\mathrm{C}-\mathrm{O}) \mathrm{cm}^{-1} \cdot{ }^{1} \mathrm{H}$ NMR $(300 \mathrm{MHz}$, DMSO-d $\left._{6}\right) \delta: 9.79(\mathrm{~s}, 1 \mathrm{H}, \mathrm{OH}), 9.22\left(\mathrm{~d}, 1 \mathrm{H}, J=1.2 \mathrm{~Hz}, \mathrm{H} 3_{\mathrm{pyr}}\right), 8.55\left(\mathrm{dd}, 1 \mathrm{H}, J_{l}=2.4 \mathrm{~Hz}, J_{2}=\right.$ $\left.1.5 \mathrm{~Hz}, \mathrm{H} 5_{\text {pyr }}\right), 8.47$ (d, 1H, $\left.J=2.7 \mathrm{~Hz}, \mathrm{H} 6_{\text {pyr }}\right), 7.94$ (d, 1H, $\left.J=3.9 \mathrm{~Hz} \mathrm{H} \mathrm{H}_{\mathrm{Th}}\right), 7.56(\mathrm{~d}, 2 \mathrm{H}, J=$ $\left.8.7 \mathrm{~Hz}, \mathrm{H}_{\mathrm{Ph}}\right), 7.43\left(\mathrm{~d}, 1 \mathrm{H}, J=3.9 \mathrm{~Hz}, \mathrm{H}_{\mathrm{Th}}\right), 6.84\left(\mathrm{~d}, 2 \mathrm{H}, J=8.7 \mathrm{~Hz}, \mathrm{H}_{\mathrm{Ph}}\right) .{ }^{13} \mathrm{C} \mathrm{NMR}(75 \mathrm{MHz}$, DMSO-d $\left._{6}\right) \delta: 163.1,153.0,152.6,149.2,147.5,145.6,143.7,133.2,132.2,129.7,128.5$, 121.2. HRMS (ESI/ASAP) $m / z$ : calculated for $\mathrm{C}_{14} \mathrm{H}_{11} \mathrm{~N}_{2} \mathrm{OS}[\mathrm{M}+\mathrm{H}]^{+}$255.0587, found 255.0587 .

2-(5-(4-Hydroxyphenyl)thiophen-2-yl)quinoxaline (6). Obtained from 2-(5-bromothiophen2-yl)quinoxaline (291 mg, $1 \mathrm{mmol})$. Yellow solid. $71 \%(216 \mathrm{mg})$. m.p.: $242^{\circ} \mathrm{C}$ (dec.). IR (KBr) v: $2978(\mathrm{O}-\mathrm{H}), 1555(\mathrm{C}=\mathrm{C}), 1441(\mathrm{C}=\mathrm{C}), 1279(\mathrm{C}-\mathrm{O}) \mathrm{cm}^{-1} .{ }^{1} \mathrm{H}$ NMR $(300 \mathrm{MHz}$, DMSO-d $\left._{6}\right) \delta: 9.55\left(\mathrm{~s}, 1 \mathrm{H}, \mathrm{H} 3_{\text {quinox }}\right), 8.19\left(\mathrm{~d}, J=3.9 \mathrm{~Hz}, 1 \mathrm{H}, \mathrm{H}_{\mathrm{Th}}\right), 8.00-8.07$ (m, 2H, $\left.\mathrm{H}_{\text {quinox }}\right)$, 7.74-7.86 (m, 2H, $\left.\mathrm{H}_{\text {quinox }}\right), 7.60\left(\mathrm{~d}, J=8.7 \mathrm{~Hz}, \mathrm{H}_{\mathrm{Ph}}\right), 7.48\left(\mathrm{~d}, J=3.9 \mathrm{~Hz}, 1 \mathrm{H}, \mathrm{H}_{\mathrm{Th}}\right), 6.82(\mathrm{~d}, J=$ $\left.8.7 \mathrm{~Hz}, \mathrm{H}_{\mathrm{Ph}}\right) .{ }^{13} \mathrm{C}$ NMR (75 MHz, DMSO-d 6 ) $\delta: 159.5,148.9,147.1,142.5,141.2,140.4$, 138.6, 130.6, 130.0, 129.0, 128.8, 128.2, 127.1, 123.2, 122.9, 116.2. HRMS (ESI/ASAP) $\mathrm{m} / \mathrm{z}$ : calculated for $\mathrm{C}_{14} \mathrm{H}_{11} \mathrm{~N}_{2} \mathrm{OS}[\mathrm{M}+\mathrm{H}]^{+}$305.0743, found 305.0741. 
(E)-2-(2-(4'-Hydroxy-[1,1'-biphenyl]-4-yl)vinyl)pyrazine (7). Obtained from (E)-2-(4bromostyryl)pyrazine $^{41}(261 \mathrm{mg}, 1 \mathrm{mmol})$. Pale yellow solid. $31 \%(85 \mathrm{mg})$. m.p.: $208^{\circ} \mathrm{C}$ (dec). IR (KBr) v: $3015(\mathrm{OH}), 1467(\mathrm{C}=\mathrm{C}), 1439(\mathrm{C}=\mathrm{C}), 1278(\mathrm{C}-\mathrm{O}) \mathrm{cm}^{-1} .{ }^{1} \mathrm{H}$ NMR (500 MHz, DMSO-d 6 ) $\delta: 9.62(\mathrm{~s}, 1 \mathrm{H}, \mathrm{OH}), 8.80\left(\mathrm{~d}, 1 \mathrm{H}, J=1.5 \mathrm{~Hz}, \mathrm{H} 3_{\mathrm{pyr}}\right), 8.62\left(\mathrm{dd}, 1 \mathrm{H}, J_{1}=2.5\right.$ $\left.\mathrm{Hz}, J_{2}=1.5 \mathrm{~Hz}, \mathrm{H} 5_{\text {pyr }}\right), 8.49\left(\mathrm{~d}, 1 \mathrm{H}, J=2.5 \mathrm{~Hz}, \mathrm{H} 6_{\text {pyr }}\right), 7.80\left(\mathrm{~d}, 1 \mathrm{H}, J=16 \mathrm{~Hz} \mathrm{H}_{\text {vinyl }}\right), 7.73$ (d, $\left.2 \mathrm{H}, J=8.5 \mathrm{~Hz}, \mathrm{H}_{\mathrm{Ph}}\right), 7.65\left(\mathrm{~d}, 2 \mathrm{H}, J=8.5 \mathrm{~Hz}, \mathrm{H}_{\mathrm{Ph}}\right), 7.56\left(\mathrm{~d}, 2 \mathrm{H}, J=8.5 \mathrm{~Hz}, \mathrm{H}_{\mathrm{Ph}}\right), 7.40(\mathrm{~d}, 1 \mathrm{H}$, $\left.J=16 \mathrm{~Hz} \mathrm{H}_{\text {vinyl }}\right), 6.86\left(\mathrm{~d}, 2 \mathrm{H}, J=8.5 \mathrm{~Hz}, \mathrm{H}_{\mathrm{Ph}}\right) .{ }^{13} \mathrm{C}$ NMR $\left(125 \mathrm{MHz}, \mathrm{DMSO}-\mathrm{d}_{6}\right) \delta: 157.9$, $151.3,145.0,144.3,143.4,141.0,134.5,134.4,130.6,128.4,128.2,126.7,124.4,114.3$. HRMS (ESI/ASAP) $m / z$ : calculated for $\mathrm{C}_{18} \mathrm{H}_{15} \mathrm{~N}_{2} \mathrm{O}[\mathrm{M}+\mathrm{H}]^{+}$275.1179, found 275.1181.

4-(5-(4-Methoxyxyphenyl)thiophen-2-yl)pyrimidine (3OMe). Obtained according to a similar procedure from 4-(5-bromothiophen-2-yl)pyrimidine ${ }^{48}(241 \mathrm{mg}, \quad 1 \mathrm{mmol})$ and 4 methoxyphenylboronic acid (228 mg, $1.5 \mathrm{mmol})$. Pale yellow solid. 81\% (217 mg). m.p. 144$146^{\circ} \mathrm{C} .{ }^{1} \mathrm{H}$ NMR $\left(300 \mathrm{MHz}, \mathrm{CDCl}_{3}\right) \delta: 9.08\left(\mathrm{~d}, 1 \mathrm{H}, J=1.0 \mathrm{~Hz}, \mathrm{H} 2_{\mathrm{pyr}}\right) 8.77$ (d, 1H, J=5.5 Hz, H6 $\left.6_{\text {pyr }}\right), 8.06\left(\mathrm{~d}, 1 \mathrm{H}, J=4.0 \mathrm{~Hz} \mathrm{H}_{\mathrm{Th}}\right), 7.99\left(\mathrm{dd}, 1 \mathrm{H}, J_{1}=5.5 \mathrm{~Hz}, J_{2}=1.0 \mathrm{~Hz}, \mathrm{H} 5_{\mathrm{pyr}}\right), 7.71(\mathrm{~d}$, $\left.2 \mathrm{H}, J=9.0 \mathrm{~Hz}, \mathrm{H}_{\mathrm{Ph}}\right), 7.55\left(\mathrm{~d}, 1 \mathrm{H}, J=4.0 \mathrm{~Hz}, \mathrm{H}_{\mathrm{Th}}\right), 7.02\left(\mathrm{~d}, 2 \mathrm{H}, J=9.0 \mathrm{~Hz}, \mathrm{H}_{\mathrm{Ph}}\right) .{ }^{13} \mathrm{C} \mathrm{NMR}$

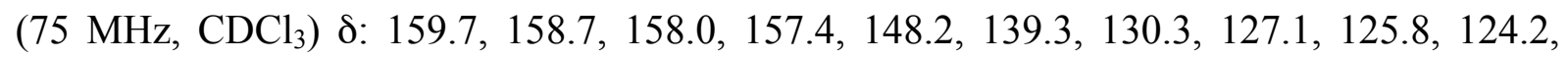
115.0, 114.6, 55.3. HRMS (ESI/ASAP) $m / z$ : calculated for $\mathrm{C}_{15} \mathrm{H}_{13} \mathrm{~N}_{2} \mathrm{OS}[\mathrm{M}+\mathrm{H}]^{+}$269.0743, found 269.0742 .

\section{Acknowledgments}

Funding from the Junta de Comunidades de Castilla-La Mancha/FEDER is gratefully acknowledged by J. R.-L. and S. A. (project SBPLY/17/180501/000214). Calculations were performed at ISCR and the work was granted access to the HPC resources of TGCC/CINES/IDRIS under the allocation 2021-A0100800649 made by Grand Equipement National de Calcul Intensif (GENCI). 


\section{References}

a) S. R. Forrest and M. E. Thompson, Chem. Rev. 2007, 107, 923-1386; b) O. Ostroverkhova, Chem. Rev. 2016, 116, 13279-13412; c) F. Bureš, RSC Adv. 2014, 4, 5882658851.

2 a) P. H. P. R. Carvalho, J. R. Correa, B. C. Guido, C. C. Gatto, H. C. B. De Oliveira, T. A. Soares and B. A. D. Neto, Chem. Eur. J. 2014, 20, 15360-15374; b) H. G. Lu, Y. D. Zheng, X. W. Zhao, L. J. Wang, S. Q. Ma, X. Q. Hzan, B. Xu, W. J. Tian and H. Gao, Angew. Chem. Int. Ed. 2016, 55, 155-159; c) W. Chen, S. Xu, J. J. Day, D. Wang and M. Xian, Angew. Chem. Int. Ed. 2017, 56, 16611-16615.

${ }^{3}$ a) X. Qian, Y.-Z. Zhu, W.-Y. Chang, J. Song, B. Pan, L. Lu, H.-H. Gao and J.-Y. Zheng, ACS Appl. Mater. Interfaces 2015, 7, 9015-9022; b) X. M. Ren, S. H. Jiang, M. Y. Cha, G. Zhou and Z.-S. Wang, Chem. Mater. 2012, 24, 3493-3499; c) J. Yang, P. Ganesan, J. Teuscher, T. Moehl, Y. J. Kim, C. Yi, P. Comte, K. Pei, T. W. Holcombe, M. K. Nazeeruddin, J. L. Huo, S. M. Zakeeruddin, H. Tian and M. Grätzel, J. Am. Chem. Soc. 2014, 136, 5722-5730.

${ }^{4}$ a) C. H. Duan, F. Huang and Y. Cao, J. Mater. Chem. 2012, 22, 10416-10434; b) M. Scarongella, A. Laktionov, U. Rothlisberger and N. Banerji, J. Mater. Chem. C 2013, 1, $2308-2319$.

${ }^{5}$ a) Y. Tao, K. Yan, T. Chen, P. Xu, H. Li, R. Chen, C. Zheng, L. Zhang and W. Huang, Adv. Mater. 2014, 26, 7931-7958; b) R. Furue, K. Matsuo, Y. Ashikari, H. Ooka, N. Amanokura and T. Yasuka, Adv. Opt. Mater. 2018, 6, 1701147. 
${ }^{6}$ a) J. Liu, W. Gao, I. V. Kityk, X. Liu and Z. Zhen, Dyes Pigm. 2015, 122, 74-84; b) J. M. Raimundo, P. Blanchard, N. Gallego-Planas, N. Mercier, I. Ledoux-Rak, R. Hierle and J. Roncali, J. Org. Chem. 2002, 67, 205-218.

${ }^{7}$ a) P. N. He, G. S. Tan, L. S. Zheng and Q. Prasad, Chem. Rev. 2008, 108, 1245-1330; b) F. Terenziani, A. Painelli, C. Katan, M. Charlot and M. Blanchard-Desce, J. Am. Chem. Soc. 2006, 128, 15742-15755

${ }^{8}$ a) M. Irie, S. Kobatake and M. Horichi, Science 2001, 291, 1769-1772; b) F. M. Raymo and M. Tomasulo, Chem. Soc. Rev. 2005, 34, 327-336; c) B. J. Coe, Acc. Chem. Res. 2006, 39, 383-396; d) P.-X. Li, M.-S. Wang, M.-J. Zhang, C.-S. Lin, L.-Z. Cai, S.-P. Guo, G.-C. Guo, Angew. Chem. Int. Ed. 2014, 53, 11529-11531; e) F. Castet, V. Rodriguez, J.-L . Pozzo, L. Ducasse, A. Plaquet and B. Champagne, Acc. Chem. Res. 2013, 46, 2556-2665.

9 a) V. Guerchais, L. Ordronneau and H. le Bozec, Coord. Chem. Rev. 2010, 254, 2533-2545;

b) F. Bondu, J. Quertinmont, V. Rodriguez, J.-L. Pozzo, A. Plaquet, B. Champagne and F. Castet, Chem. Eur. J. 2015, 27, 18749-18757; c) L. Casimiro, S. Maisonneuve, P. Retailleau, S. Silvi, J. Xie and R. Métivier, Chem. Eur. J. 2020, 26, 14341-14350; d) H. Zhao, E. Garoni, T. Roisnel, A. Colombo, C. Dragonetti, D. Mariotto, S. Righetto, D. Roberto, D. Jacquemin, J. Boixel and V. Guerchais, Inorg. Chem. 2018, 57, 7051-7063.

${ }^{10}$ a) C. E. Powell, M. G. Humphrey, M. P. Cifuences, J. P. Morrall, M. Samoc and B. LutherDavies, J. Phys. Chem. A 2003, 107, 11264-11266; b) A. Belén Marco, P. Mayorga Buzzezo, L. Mosteo, S. Franco, J. Garín, J. Orduna, B. E. Diosdado, B. Villacampa, J. T. LópezNavarrete, J. Casado and R. Andreu, $R S C A d v .2015,5$, 231-242; c) S. Kim and Y. You, $A d v$. Opt. Mater. 2019, 7, 190020; d) M. Walęsa-Chorab, C. Yao, G. Tuner and W. G. Skene, Chem. Eur. J. 2020, 26, 17416-17427.

${ }^{11}$ a) E. Cariati, C. Botta, S. G. Danelli, A. Forni, A. Giaretta, U. Giovanella, E. Lucenti, D. Marinotto, S. Righetto and R. Ugo, Chem. Commun. 2014, 50, 14225-14228; b) J. Yang, X. 
Liu, Z. Liu, L. Wang, J. Sun, Z. Guo, H. Xu, H. Wang, B. Zhao and G. Xie, J. Mater. Chem. C 2020, 8, 2442-2450; c) D. Liu, Z. Zhang, H. Zhang and Y. Wang, Chem. Commun. 2013, 49, 10001-10003.

12 a) M. Zheng, M. Sun, D. Zhang, T. Liu, S. Xue and W. Yang, Dyes Pigm. 2014, 101, 109115; b) M. Hauck, J. Scönhaber, A. J. Zucchero, K. I. Hardcastle, T. J. J. Müller and U. H. F. Bunz, J. Org. Chem. 2007, 72, 6714-6725; c) Y. Shiraishi, C. Ichimura, S. Sumiya and T. Harai, Chem. Eur. J. 2011, 17, 8324-8332; d) J. N. Wilson and U. H. F. Bunz, J. Am. Chem. Soc. $2005, \mathbf{1 2 7}, 4124-4125$.

${ }^{13}$ S. Achelle, J. Rodríguez-López, F. Bureš and F. Robin-le Guen, Dyes Pigm. 2015, 121, $305-311$.

14 a) S. Achelle, J. Rodríguez-López and F. Robin-le Guen, ChemistrySelect 2018, 3, $1852-$ 1886; b) G. N. Lipunova, E. V. Nosova, V. N. Charushin and O. N. Chupakhin, Curr. Org. Synth. 2018, 15, 793-814; c) R. Komatsu, H. Sasabe and J. Kido, J. Photon. Energy 2018, 8, 032108.

15 a) S. Achelle, C. Baudequin and N. Plé, Dyes Pigm. 2013, 98, 575-600; b) K. Hoffert, R. J. Durand, S. Gauthier, F. Robin-le Guen and S. Achelle, Eur. J. Org. Chem. 2017, 523-529; c) P. Meti, H.-H. Park and Y.-D. Gong, J. Mater. Chem. C 2020, 8, 352-379.

${ }^{16}$ S. Achelle, J. Rodríguez-López, F. Bureš, F. Robin-le Guen, Chem. Rec. 2020, 20, 440451.

${ }^{17}$ C. Hadad, S. Achelle, I. López-Solera, J. García-Martínez and J. Rodríguez-López, Dyes Pigm. 2013, 97, 230-237.

18 a) S. Yan, R. Huang, Y. Zhou, M. Zhang, M. Deng, X. Wang, X. Weng and X. Zhou, Chem. Commun. 2011, 47, 1273-1275; b) A. Boländer, D. Kiesner, C. Voss, S. Bauer, C. Schön, S. Burgold, T. Bittner, J. Hölzer, R. Heyny-von Haußen, G. Mall, V. Goetchy, C. 
Czech, H. Knust, R. Berber, J. Herms, I. Hilger and B. Schmidt, J. Med. Chem. 2012, 55, 9170-9180.

${ }^{19}$ a) H. Wang, J. Wang, T. Zhang, Z. Xie, X. Zhang, H. Sun, Y. Xiao, T. Yu and W. Huang, J. Mater. Chem. C, 2021, 9, 10154-10172 ; b) J. Massue, D. Jacquemin and G. Ulrich, Chem. Lett., 2018, 47, 1083-1089.

${ }^{20}$ a) S. Achelle, J. Rodríguez-López, N. Cabon and F. Robin-le Guen, RSC Adv. 2015, 5, 107396-107399; b) S. Achelle, J. Rodríguez-López, C. Katan and F. Robin-le Guen, J. Phys. Chem. C, 2016, 120, 26586-26995; c) S. Achelle, J. Rodríguez-López, M. Larbani, R. PlazaPedroche and F. Robin-le Guen, Molecules, 2019, 24, 1742.

${ }^{21}$ H. Muraoka, N. Iwabuchi and S. Ogawa, Bull. Chem. Soc. Jpn. 2019, 92, 1358-1369.

${ }^{22}$ A. D. Laurent and D. Jacquemin, Int. J. Quantum Chem. 2013, 113, 2019-2039.

${ }^{23}$ C. Adamo and D. Jacquemin, Chem. Soc. Rev. 2013, 42, 845-856.

${ }^{24}$ A. D. Laurent, C. Adamo and D. Jacquemin, Phys. Chem. Chem. Phys. 2014, 16, 14334 14356.

${ }^{25}$ H. Li, R. Nieman, A. J. A. Aquino, H. Lischka and S. Tretiak, J. Chem. Theor. Comput. 2014, 10, 3280-3289.

${ }^{26}$ R. Improta, V. Barone, G. Scalmani and M. J. Frisch, J. Chem. Phys. 2006, 125, 054103.

${ }^{27}$ M. Caricato, B. Mennucci, J. Tomasi, F. Ingrosso, R. Cammi, S. Corni and G. Scalmani, J. Chem. Phys. 2006, 124, 124520.

${ }^{28}$ C. A. Guido, D. Jacquemin, C. Adamo and B. Mennucci, J. Chem. Theor. Comput. 2015, 11, 5782-5790.

${ }^{29}$ K. Veys and D. Escudero, J. Phys. Chem. A 2020, 124, 7228-7237.

${ }^{30}$ R. L. Martin, J. Chem. Phys. 2003, 118, 4775-4777.

${ }^{31}$ T. Le Bahers, C. Adamo and I. Ciofini, J. Chem. Theor. Comput. 2011, 7, 2498-2506. 
${ }^{32}$ C. Adamo, T. Le Bahers, M. Savarese, L. Wilbraham, G. García, R. Fukuda, M. Ehara, N. Rega and I. Ciofini, Coord. Chem. Rev. 2015, 304-305, 166-178.

${ }^{33}$ L. Huet, A. Perfetto, F. Muniz-Miranda, M. Campetella, C. Adamo, I. Ciofini, J. Chem. Theor. Comput. 2020, 16, 4543-4553.

${ }^{34}$ C. A. Guido, P. Cortona, B. Mennucci and C. Adamo, J. Chem. Theor. Comput. 2013, 9, $3118-3126$.

${ }^{35}$ N. H. List, R. Zaleśny, N. A. Murugan, J. Kongsted, W. Bartkowiak and H. Ågren, J. Chem. Theor. Comput. 2015, 11, 4182-4188.

${ }^{36}$ S. Achelle and F. Robin-le Guen, J. Photochem. Photobiol A 2017, 348, 281-286.

${ }^{37}$ D. H. McDaniel and H. C. Brown, J. Org. Chem. 1958, 23, 420-427.

${ }^{38}$ S. Achelle, I. Nouira, B. Pfaffinger, Y. Ramondenc, N. Plé and J. Rodríguez-López, J. Org. Chem. 2009, 74, 3711-3717.

${ }^{39}$ A. W. Kohn, Z. Lin and T. Van Voorhis, J. Phys. Chem. C 2019, 123, 15394-15402.

${ }^{40}$ Z. Lin, A. W. Kohn and T. Van Voorhis, J. Phys. Chem. C 2020, 124, 3925-3938.

${ }^{41}$ P.-F. Loos and D. Jacquemin, J. Chem. Theor. Comput. 2019, 15, 2481-2491.

${ }^{42}$ R. Lartia, C. Allain, G. Bordeau, F. Schmidt, C. Fiorini-Debuisschert, F. Charra and M.-P. Teulade-Fichou, J. Org. Chem. 2008, 73, 1732-1744.

${ }^{43}$ D. Cvejn, S. Achelle, O. Pytela, J.-P. Malval, A. Spangenberg, N. Cabon, F. Bureš and F. Robin-le Guen, Dyes Pigm. 2016, 124, 101-109.

${ }^{44}$ R. Milcent Chimie Organique Hétérocyclique, EDP Science, Les Ulis 2003.

${ }^{45}$ S. Achelle, A. Barsella, C. Baudequin, B. Caro and F. Robin-le Guen, J. Org. Chem. 2012, 77, 4087-4096.

${ }^{46}$ M. Taniguchi and J. S. lindsey, Photochem. Photobiol. 2018, 94, 290-327.

${ }^{47}$ Frisch, M. J.; Trucks, G. W.; Schlegel, H. B.; Scuseria, G. E.; Robb, M. A.; Cheeseman, J. R.; Scalmani, G.; Barone, V.; Petersson, G. A.; Nakatsuji, H.; Li, X.; Caricato, M.; Marenich, 
A. V.; Bloino, J.; Janesko, B. G.; Gomperts, R.; Mennucci, B.; Hratchian, H. P.; Ortiz, J. V.; Izmaylov, A. F.; Sonnenberg, J. L.; Williams; Ding, F.; Lipparini, F.; Egidi, F.; Goings, J.; Peng, B.; Petrone, A.; Henderson, T.; Ranasinghe, D.; Zakrzewski, V. G.; Gao, J.; Rega, N.; Zheng, G.; Liang, W.; Hada, M.; Ehara, M.; Toyota, K.; Fukuda, R.; Hasegawa, J.; Ishida, M.; Nakajima, T.; Honda, Y.; Kitao, O.; Nakai, H.; Vreven, T.; Throssell, K.; Montgomery Jr., J.; Peralta, J. E.; Ogliaro, F.; Bearpark, M. J.; Heyd, J. J.; Brothers, E. N.; Kudin, K. N.; Staroverov, V. N.; Keith, T. A.; Kobayashi, R.; Normand, J.; Raghavachari, K.; Rendell, A. P.; Burant, J. C.; Iyengar, S. S.; Tomasi, J.; Cossi, M.; Millam, J. M.; Klene, M.; Adamo, C.; Cammi, R.; Ochterski, J. W.; Martin, R. L.; Morokuma, K.; Farkas, O.; Foresman, J. B.; Fox, D. J. Gaussian 16, Revision A.03; Gaussian Inc.: Wallingford CT, 2016.

${ }^{48}$ J.-D. Chai and M. Head-Gordon, Phys. Chem. Chem. Phys. 2008, 10, 6615.

${ }^{49}$ C. Adamo and V. Barone, J. Chem. Phys. 1999, 110, 6158-6170.

${ }^{50}$ H. Peng, Y.-Q. Chen, S.-L. Mao, Y.-X. Pi, Y. Chen, Z.-Y. Lian, T. Meng, S.-H. Liu and G.A. Yu, Org. Biomol. Chem. 2014, 12, 6944-6952.

${ }^{51}$ M. Peter, R. Gleiter, F. Rominger and T. Oeser, Eur. J. Org. Chem. 2004, 3212-3220.

${ }^{52}$ E. V. Verbitskiy, E. M.; Cheprakova, P. A. Slepukhin, M. I. Kodess, M. A. Ezhikova, M. G. Pervova, G. L. Rusinov, O. N. Chupakhin and V. N. Charushin, Tetrahedron 2012, 68, $5445-5452$.

${ }^{53}$ S. Achelle, A. Barsella, B. Caro and F. Robin-le Guen, RSC Adv. 2015, 5, 39218-29227. 